\title{
صعوبات حل المسائل الفيزيائية لدى طلاب مقررات الفيزياء الأولية بجامعة الملك سعود

\author{
*هد بن سليمان الشايع
} \\ جامعة الملك سعود، الرياض، المملكة العربية السعودية
}

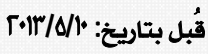

عُدل بتاريخ

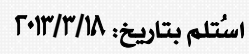

هدفت هذه الدراسة إلى تحديد الصعوبات التي يواجهها طلاب مقررات الفيزياء الأولية بجامعة الملك سعود عند حل المسائل الفيزيائية ، وذلك

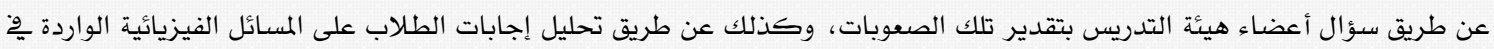

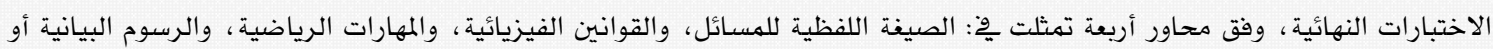

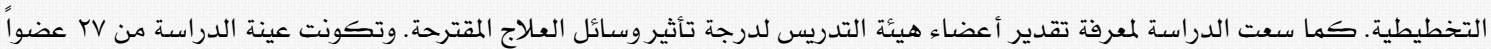

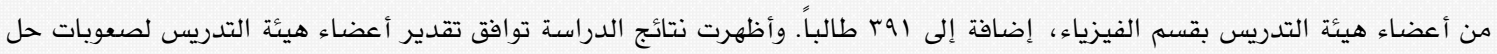

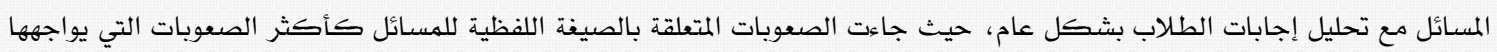

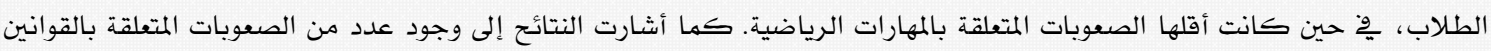
الفيزيائية ، والرسوم البيانية أو التخطيطية. كما بينت النتائج أن تقدير أعضاء هيئة التدريس لأربع عشرة وسيلة مقترحة كان كان ذا تأثير "عال".

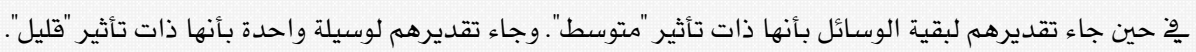
كلمات مفتاحية: صعوبات، حل المسائل الفيزيائية ، مقررات الفيزياء الجامعة الأولية، جامعة الملك سعود.

\section{Students' Difficulties in Solving Physics Problems in Introductory College Physics Courses at King Saud University}

\author{
Fahad S. Alshaya* \\ King Saud University, Riyadh, Kingdom of Saudi A rabia
}

The purpose of this study was to identify the difficulties facing students in introductory college physics courses at King Saud University in solving physics problems, by exploring faculty members' perceptions of these difficulties, and through analyzing students' answers to physics problems in final exams. The study mainly focused on four themes of difficulties, including: the problems verbal context, physics laws, mathematical skills and graphs or diagrams. The study also sought to learn about faculty's perception towards the degree of influence of the proposed solutions. The study sample consisted of 27 physics faculty members, in addition to 391 students. The study showed consistency between the faculty members' perception towards the difficulties of solving problems and the analysis of student answers in final exams. The difficulties related to the verbal context were the most common among students, whereas difficulties related to mathematical skills were the least common. In addition, the results revealed that there were also difficulties related to physical laws, and knowledge of graphs or diagrams. The findings showed that the perceptions of faculty members towards proposed solutions as being as a "high effect"on fourteen suggested techniques, while their perception towards the rest of the techniques were as "medium effect". Finally, their perception towards only one technique was being of "low effect".

Keyw ords: difficulties, solving physics problems, introductory college physics courses, King Saud University.

*alshaya@ksu.edu.sa 


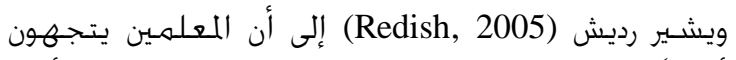

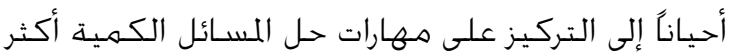

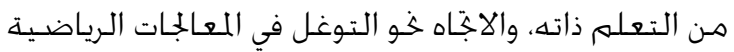

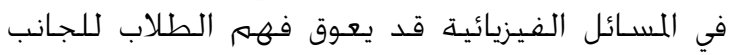

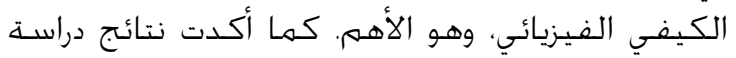

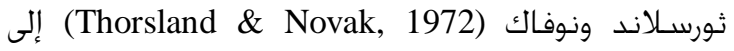

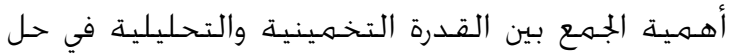

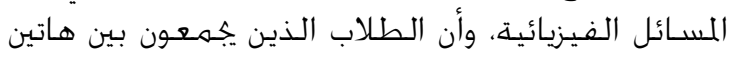

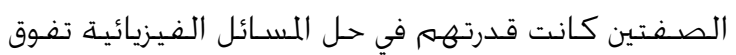

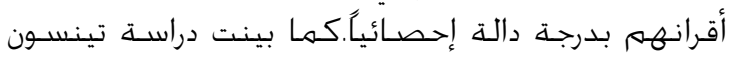

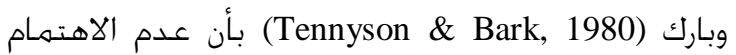

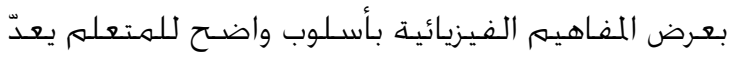

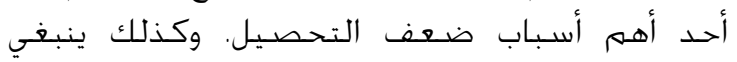
الابتعاد عن التجريد، والاجناه خو ربط المسالة بون بواقع الحياة

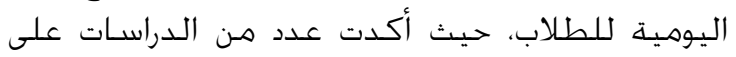

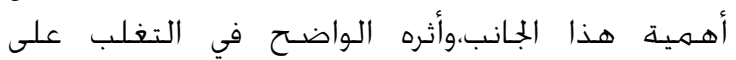

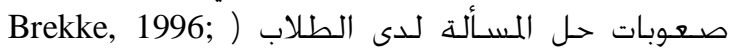
Bagayoko, Kelley \& Hasan, 2000; Park \& Lee,

. (2004

وتمثل القدرة على التعامل مع القوانين الفيزيائية

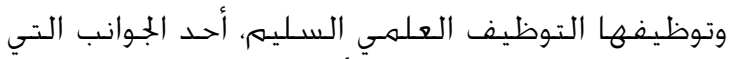
يتطلب تملك الطلاب لها من أجل حل الجل المسائل الفيزيائية.

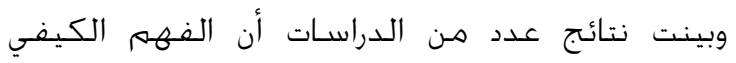

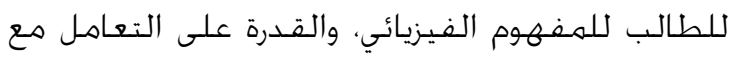

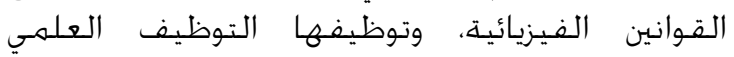
السليم، مهارة تنقص كثيراً من طلاب مقين التهرات الفيزياء

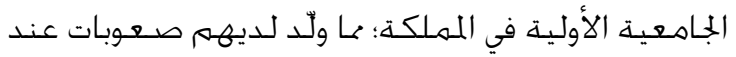

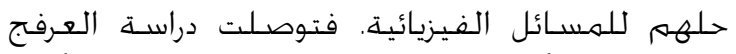

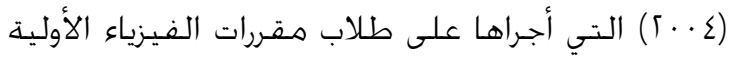

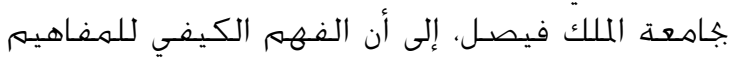

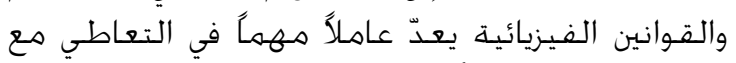

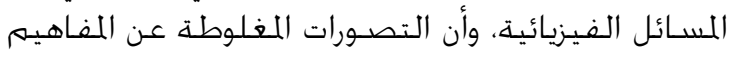

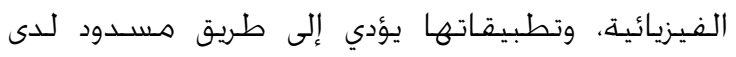

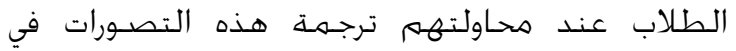
المعالجات الكمية الرياضـية.

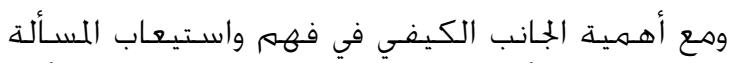

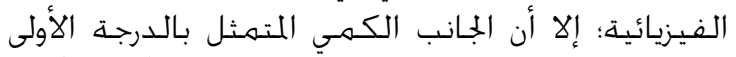

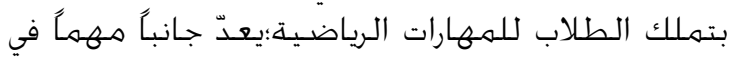

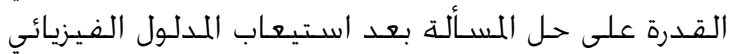
لها. ويؤكد سـامبس (Sambs, 1991) على المسأل أن المهارت الفيزيائ

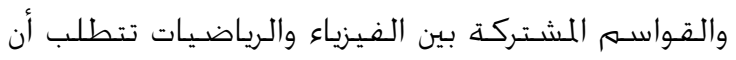

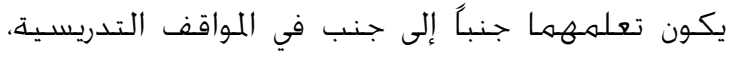

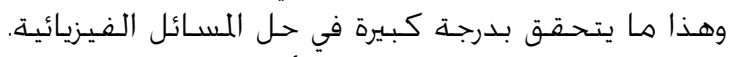

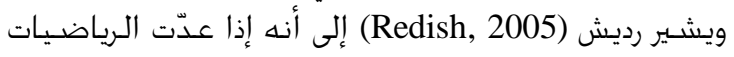
لغة العلوم، فإن الرياضيات لهجهة ميزة في لغة الفئ الفيزياء.
يعدّتملك الطلاب لمهارات حل المسائل الفيزيائية Physics)

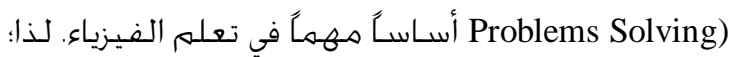

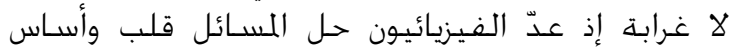

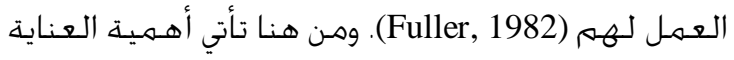

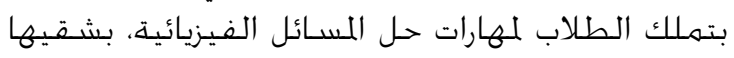

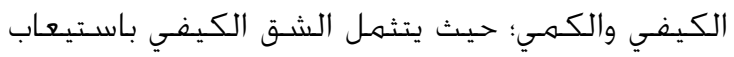

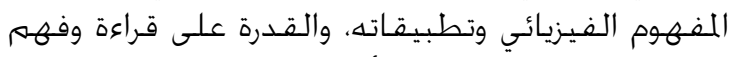

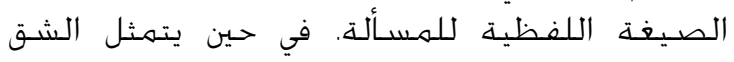

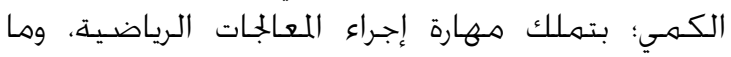

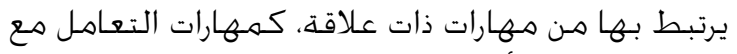

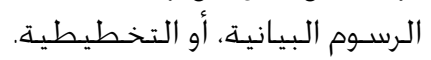

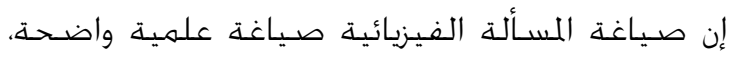

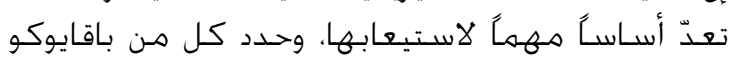

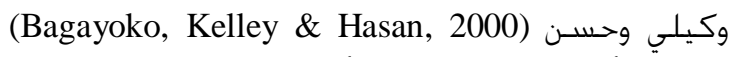

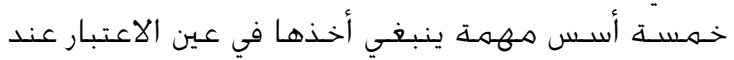

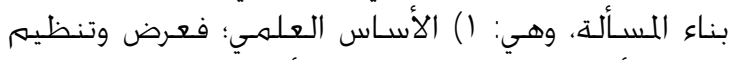

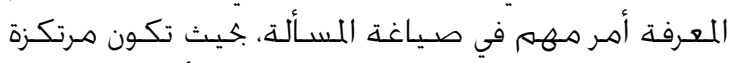

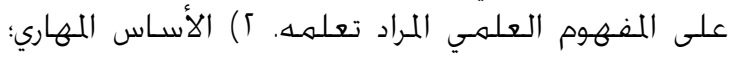

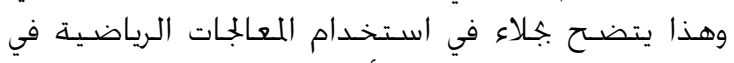

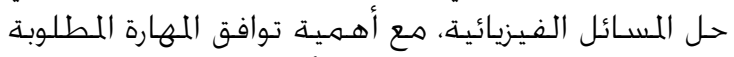

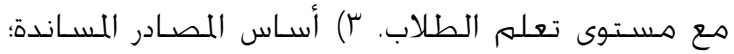

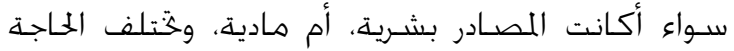

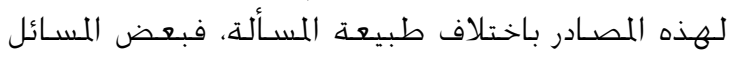

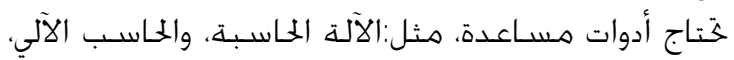

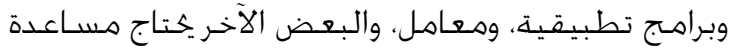

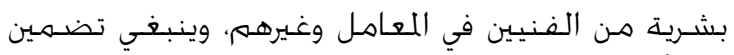

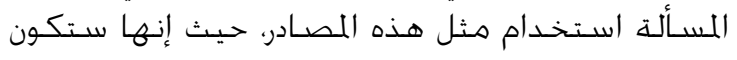

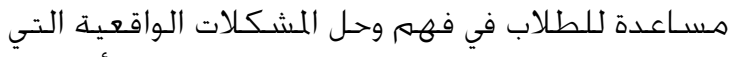

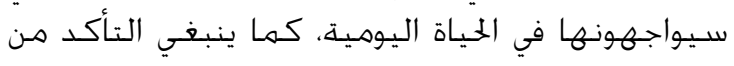

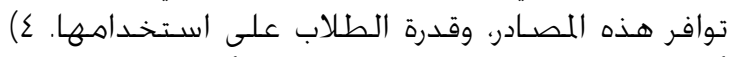

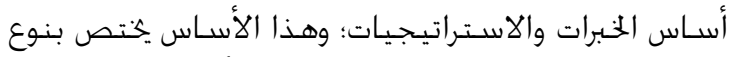

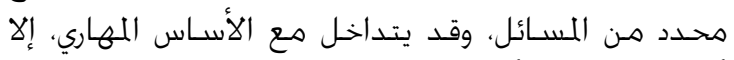

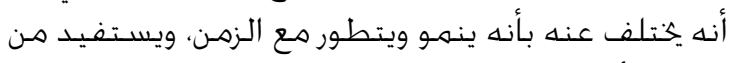

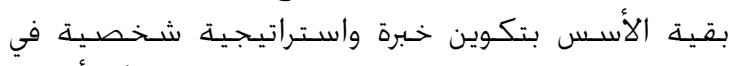

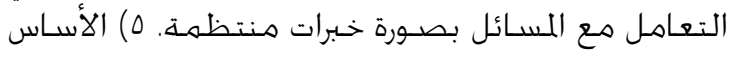

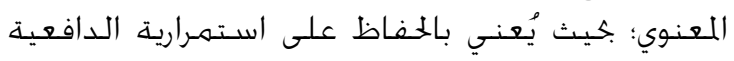

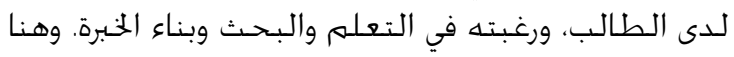

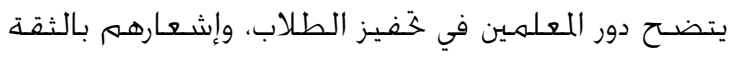
بالنفس، والقدرة على مواجهة وحل المسائل بروح قابلة للتحدي والبحث.

إن قدرة المعلم على صياغة المسألة الفيزيائية صياغة ومئة

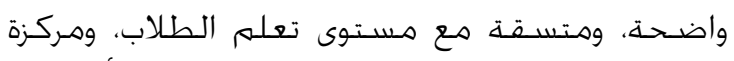

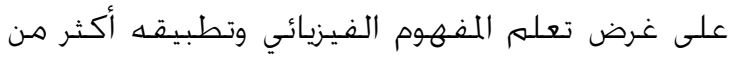

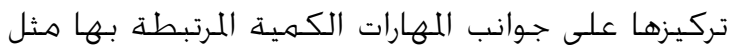

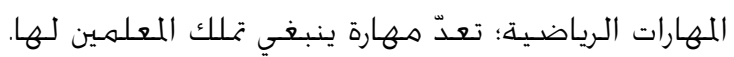


بفهم الصيغة اللفظية للمسألة أقل تلك الصعوبات

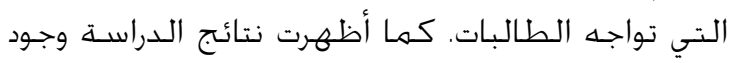

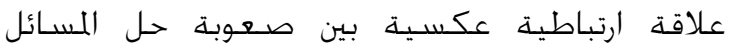
الفيزيائية، ومعدل الطالبة في مادة الرياضيات.

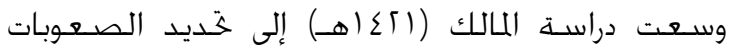

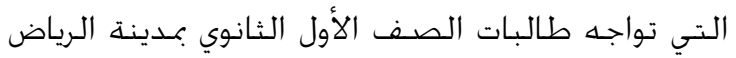

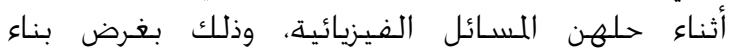

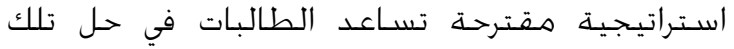

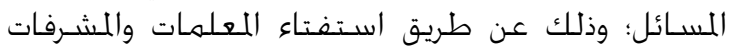

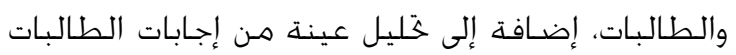

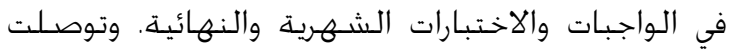

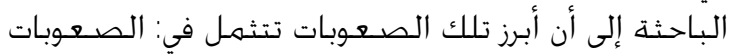

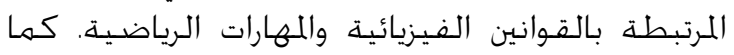

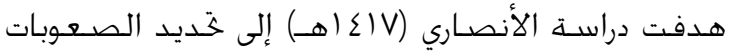

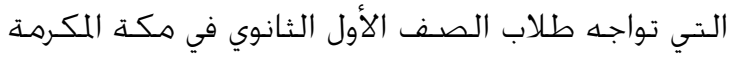

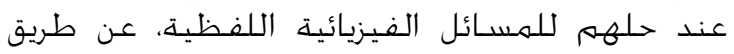

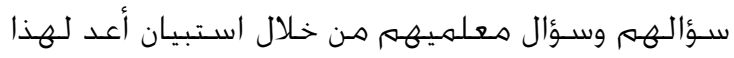

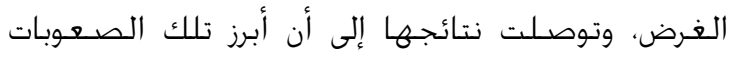

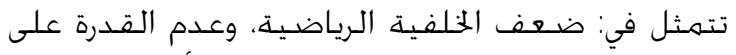

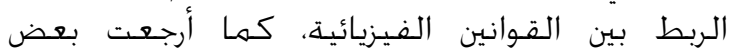

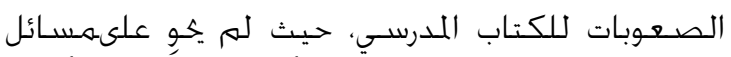

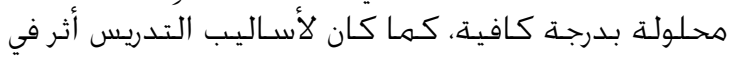

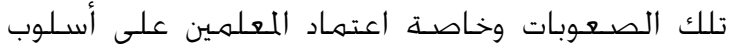

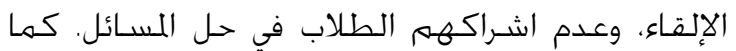

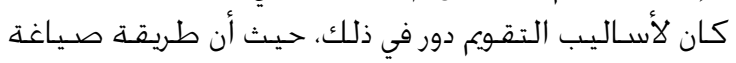

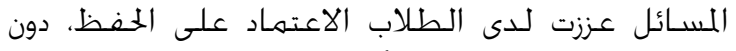

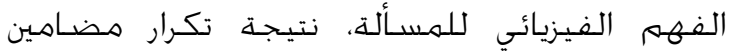

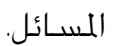

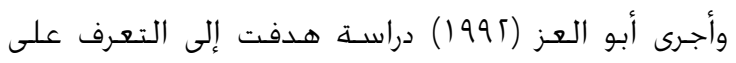

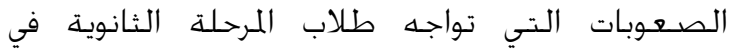

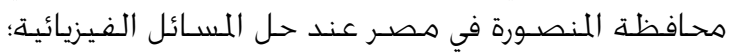

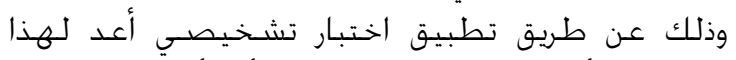

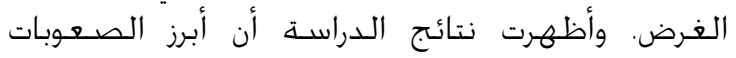

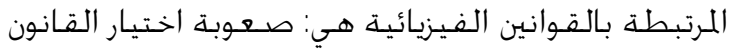

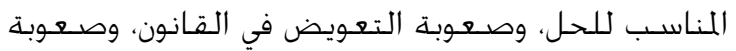

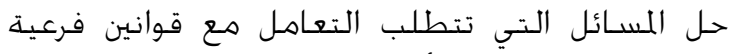

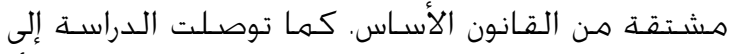

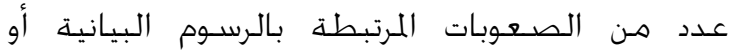

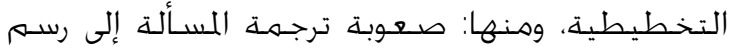

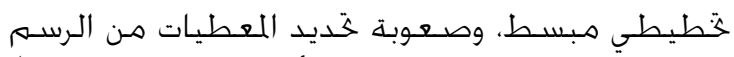

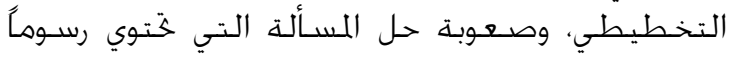

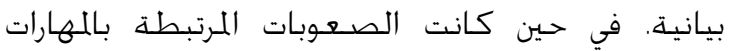

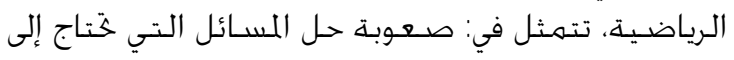

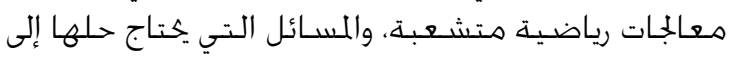

وهع إدراك هذه الأهمية والعلاقة الوطيدة بين الرياضيات

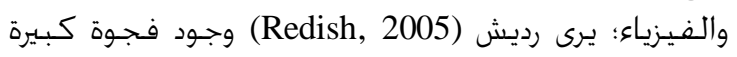

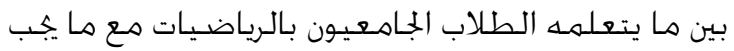

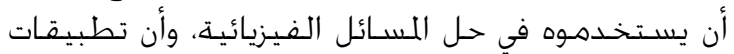

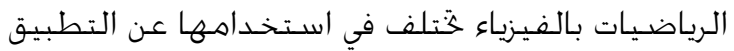

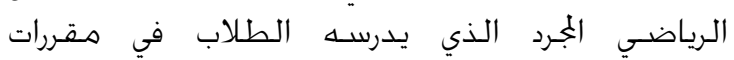

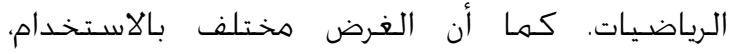

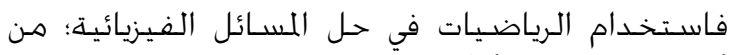

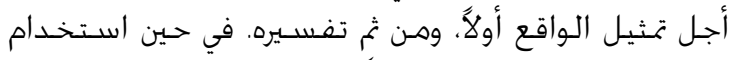

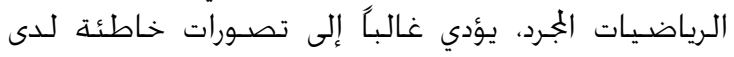

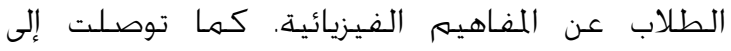

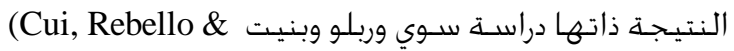

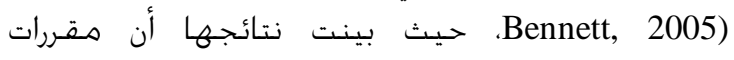

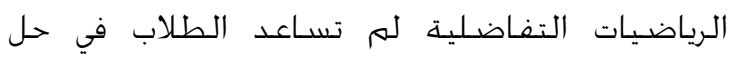

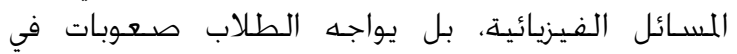
تطبيق معرفتهم الرياضية التفاضلية في المسائل في لطيائل الفيزيائية.

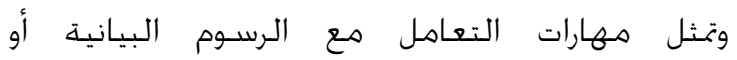

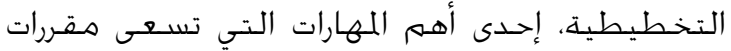

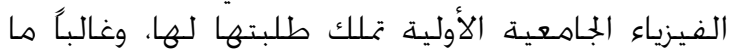
تكون متضـمنة في حل العـديد مـن المسائل الفيزيائية،

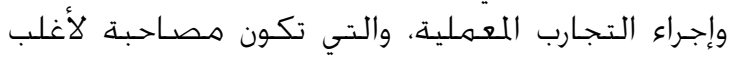

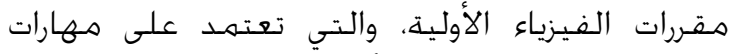

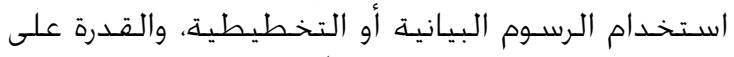

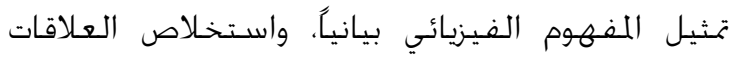

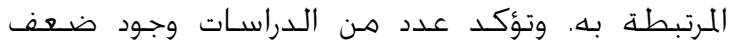

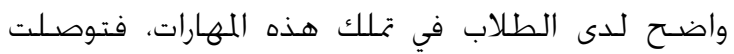

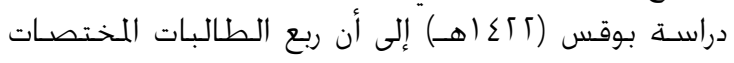

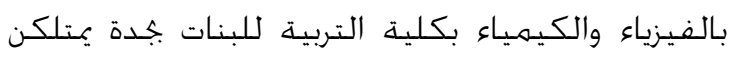

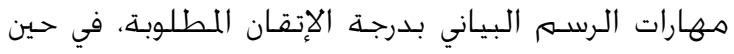
بقية الطالبات لميحققن درجة الاتقان المطلوبة.

وربط كثير من الباحثين بين مهارات الطلاب التي

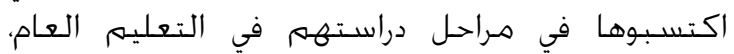

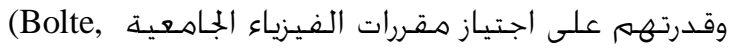
.1966; Yager \& Krajcik, 1989; Sadler \& Tai,2001) وبينت نتائج عدد من الدراسـات الملية والإقليمية

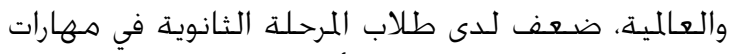

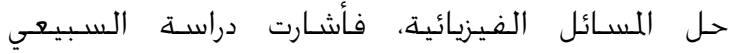

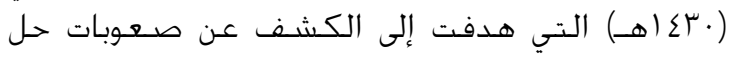

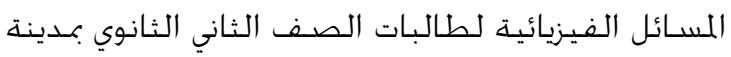

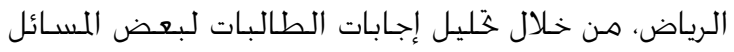

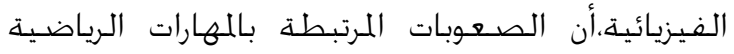

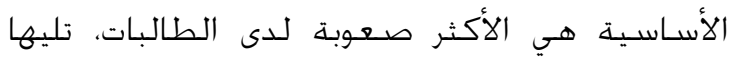

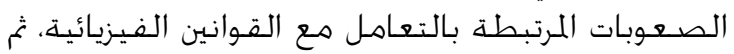
صعوبات الرسـوم البيانية، وجاءت الصعوبات المرتبطة 
الجامعات الأمريكية؛ توصل هيندرسـون وهيلر وهيلر وكيو

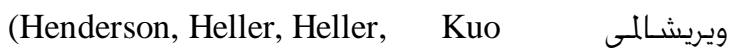
يرون \&erushalmi, 2002)

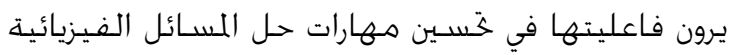

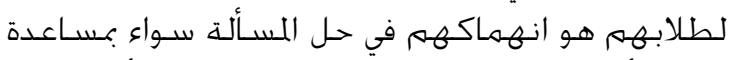

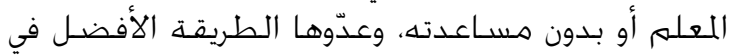

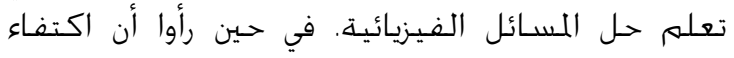

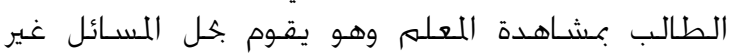
مجدي. وفي دراستهم الأخرى؛ توصله كئل كيو وهيلر وهيلر وهيلر

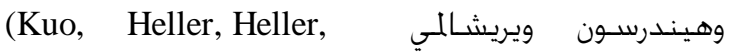
Henderson \& Yerushalmi, 2002)

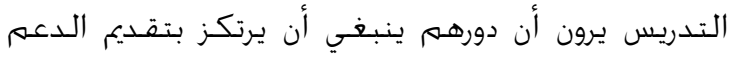

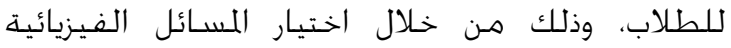

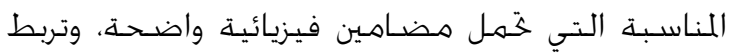

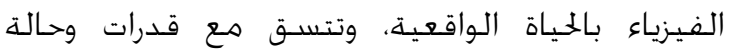

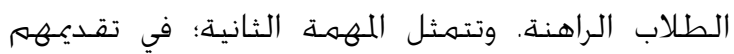
المقترحات للطلاب لتطوير مهاراتهم في حل العل المسائل،

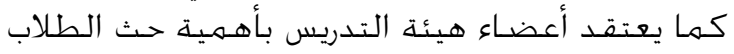

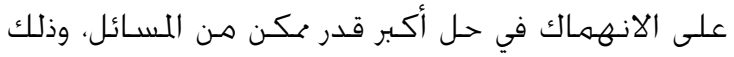

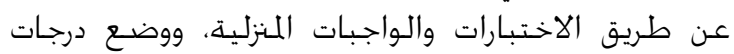

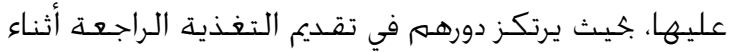

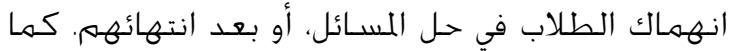

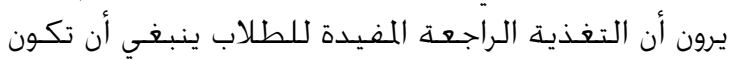

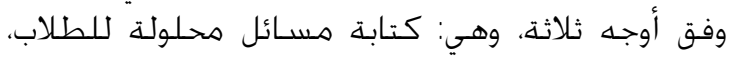

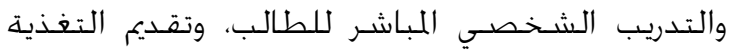

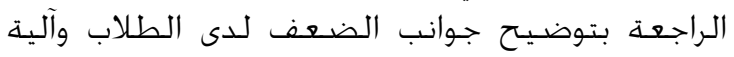

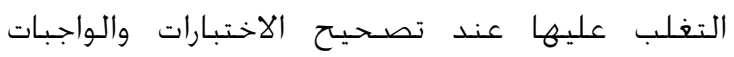

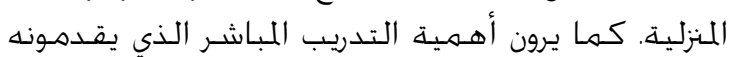
لطلبتهم المتعثرين خلال السـاعات المكتبية.

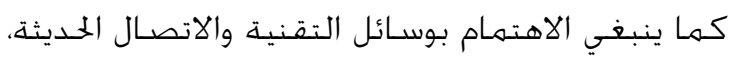

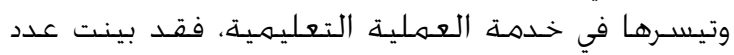

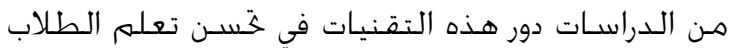

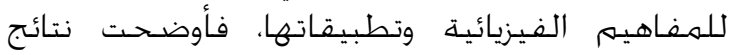
دراسـة روس وكاسي (Ross, \& Casey, 1994) فاعلية برنامج حاسـوبي في تطوير مهارات حل المسائل الفيزيائية

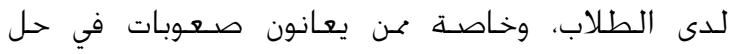

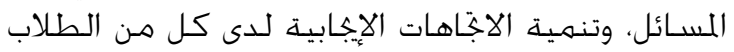

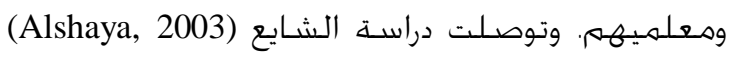

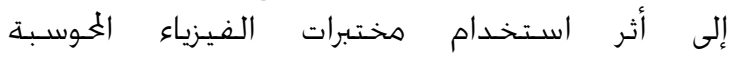
Microcomputer-based laboratory

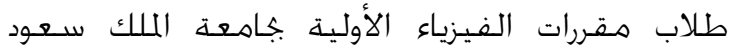

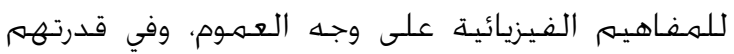

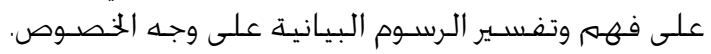

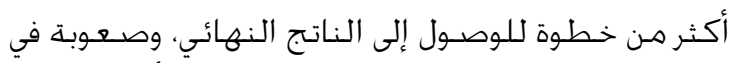
خديد العنى الفيزيائي للناتج النهائي للمسيألة.

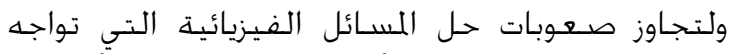

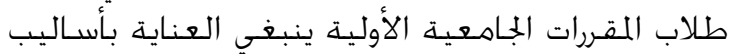

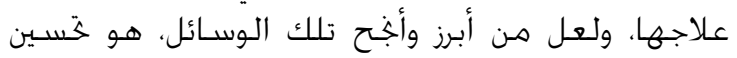

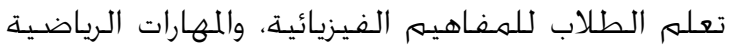

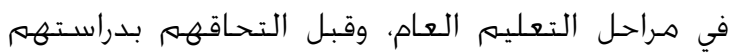

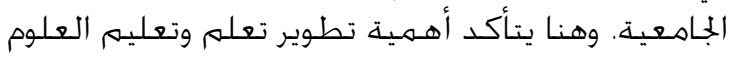

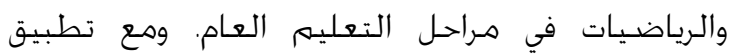

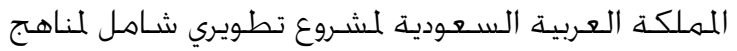
الرياضيات والعلوم الطبيعية في التعليم العام (وزارة

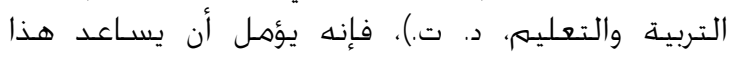

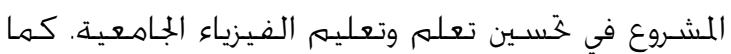

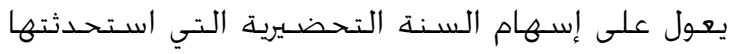

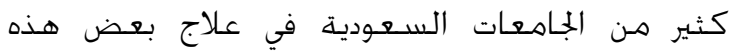

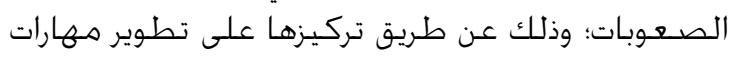
الطلاب القرائية، والرياضية، والمهارات المرتبطة بالتفيكير تركير

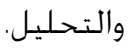
ويأتي دور أعضـاء هيئة التدريس في تعليهم الفيزياء عموهاً.

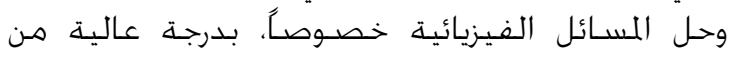

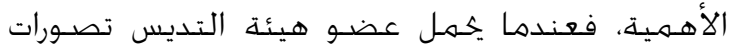

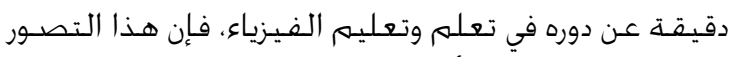

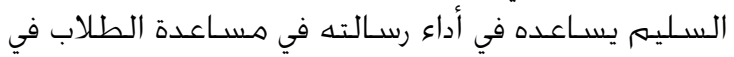

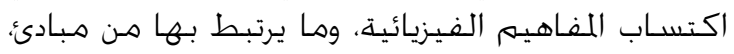

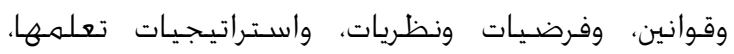

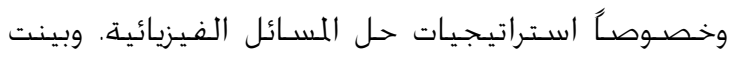

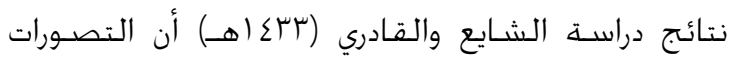

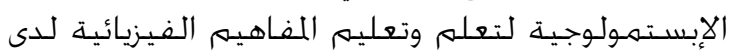

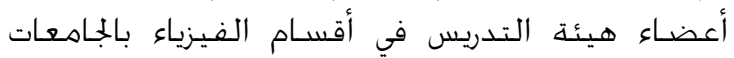

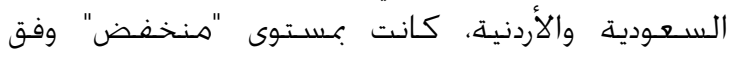

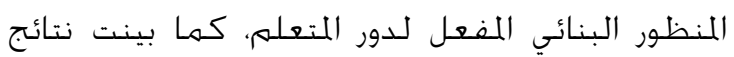

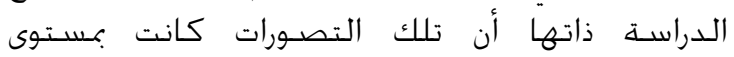

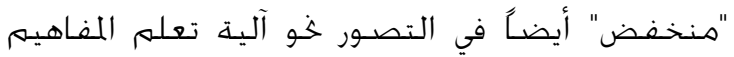
الفيزيائية، ودور عضو هيئة التدريس في في تعليمها،

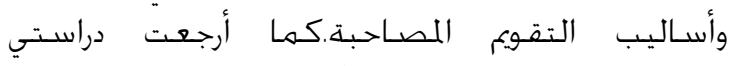

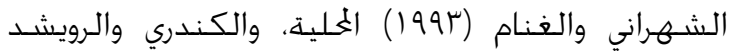

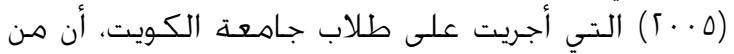

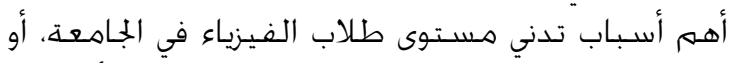

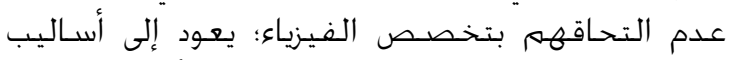

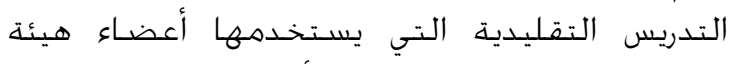

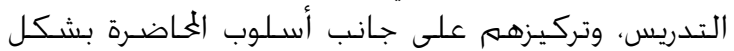

رئيسلس.

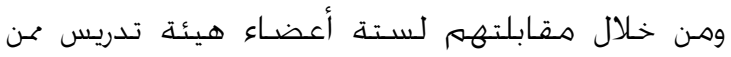
يدرسـون مقررات الفيزياء الجامعية الأولية في عدد من التهاء 
آ. ما صعوبات حل المسائل الفيزيائية المتعلقة

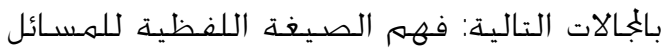

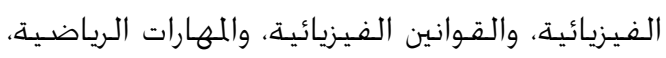

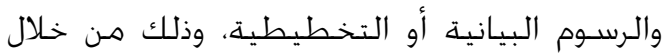
خليل إجابات الطلاب في الاختبارات النهائية؟

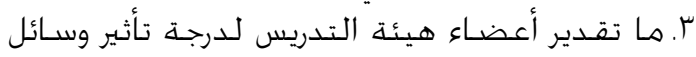

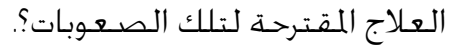

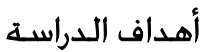

تهدف هذه الدراسـة لتحديد صعوبات حل المسائل

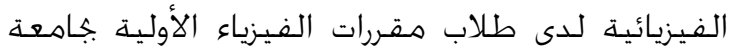
الملك سعود، وفق محاور أربعة تمثلت في: الفئياء الاولين الصيغة

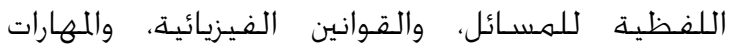

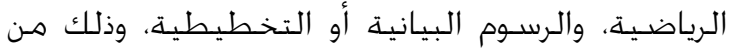

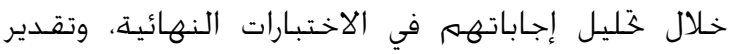

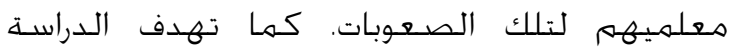
لتحديد أبرز وسـائل علاج تلك الصعوبات كهوبات كما يقترحها لدراسا أعضاء هيئة التدريس. أترز ولائ.

أهمبة الدراسة

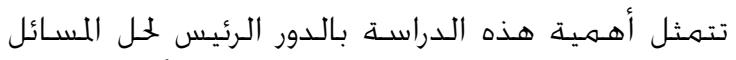

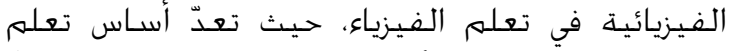

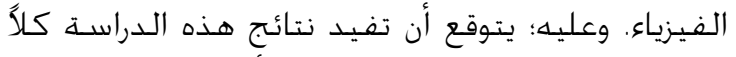
من مخططي مقررات الفيزياء الأولية بجامعة الملك الديك

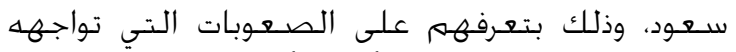
طلاب مقررات الفيزياء الأولية أثناء حلهمه للمسيائل التهات

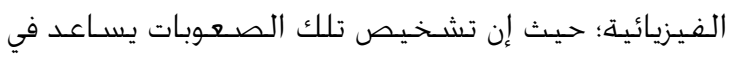
معالجة الجوانب التنظيمية في المقرر.

\section{مصطلحات الدراسـة}

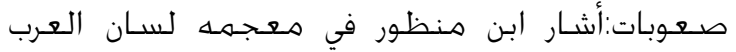

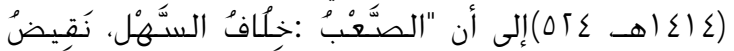

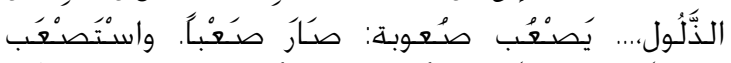

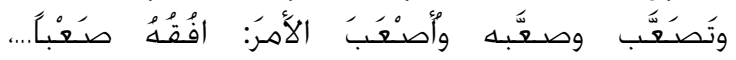

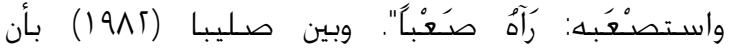

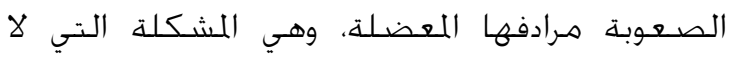

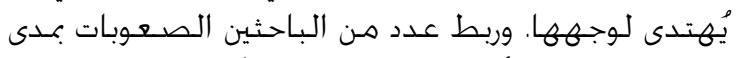

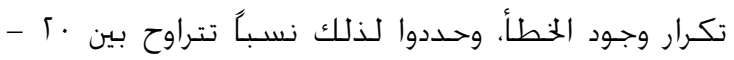

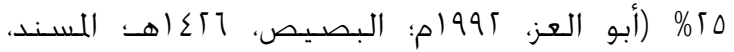
\&TV

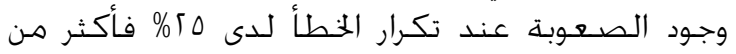

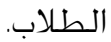

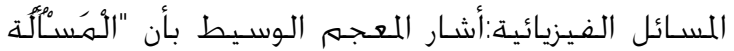

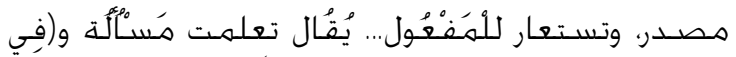

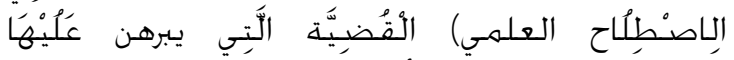

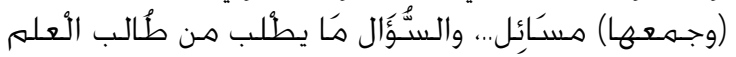

\section{صباغة المشكلة}

تمثل مهارات حل المسائل الفيزيائية إحدى أهم المهارات

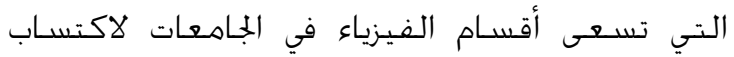

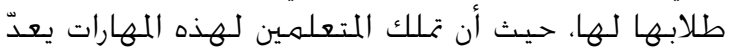

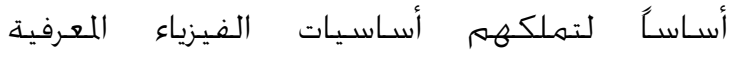

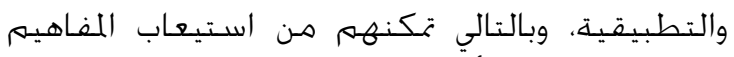

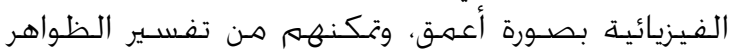

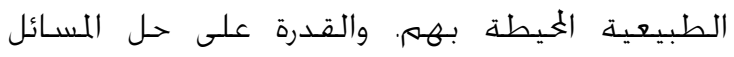

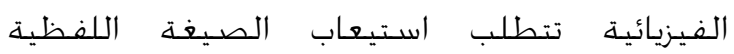

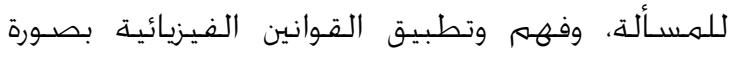

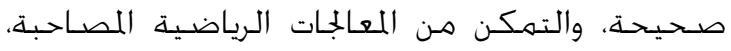

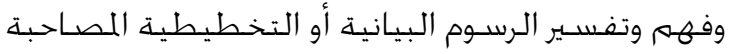

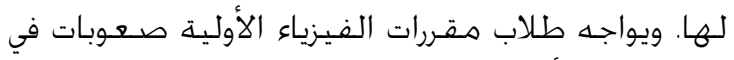

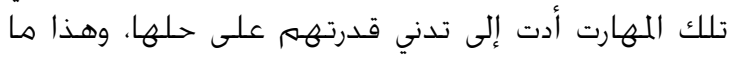

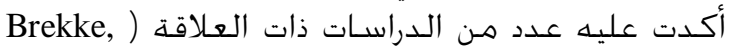
1996; Bagayoko, Kelley \& Hasan, 2000; Park \& .(Lee, 2004; Cui, Rebello \& Bennett, 2005

وأظهرت نتائج دراسـة الشايع (2013) عدم تمكن طلاب

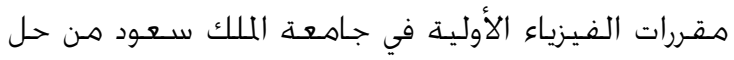

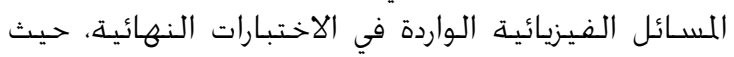

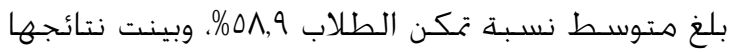

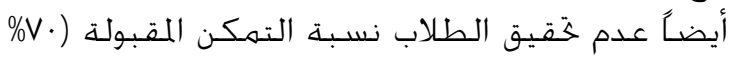

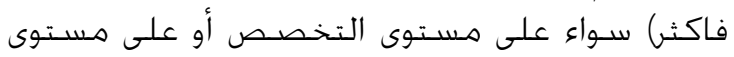

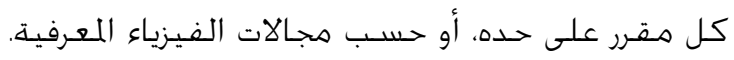

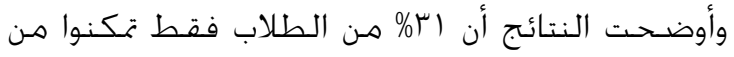

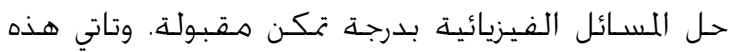

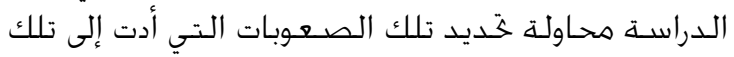

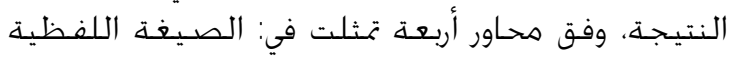

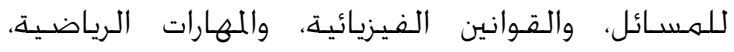

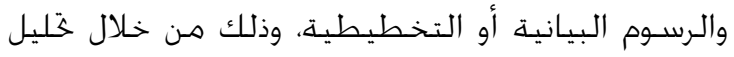

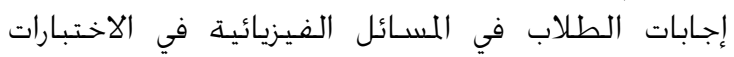

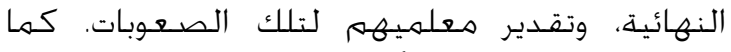

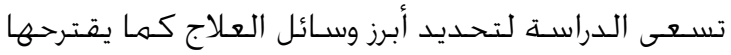

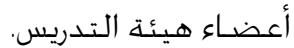

أسئلة الدراسـة

تتناول هذه الدراسـة صعوبات حل المسائل الفيزيائية

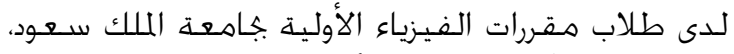
وتسعى خديداً للإجابة عن الأسئلة التالية:

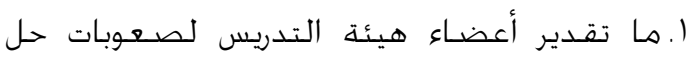

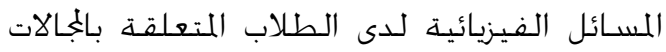

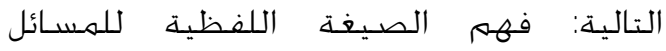

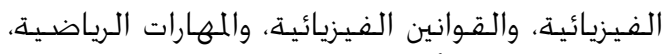
والرسـوم البيانية أو التخطيطية وانئية 


\section{مجتمع وعينة الدراسة}

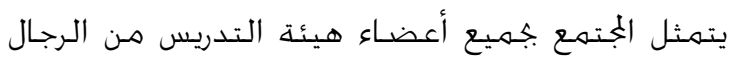

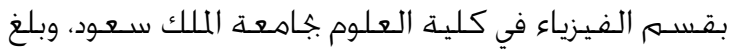

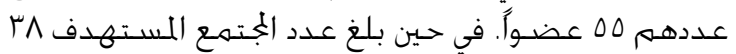

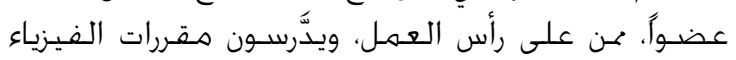

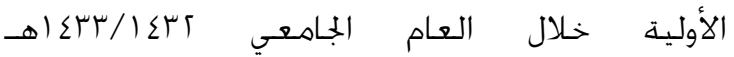

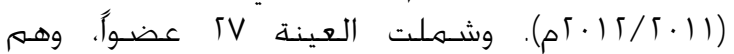

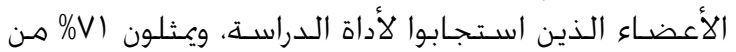

$$
\text { المجتهع المستهدف. الخفئ. }
$$

ويتمثل مجتمع الطلاب بجميع طلاب مقررات الفيزياء

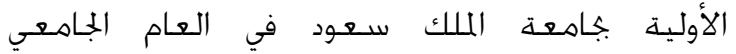

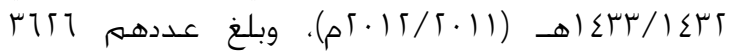

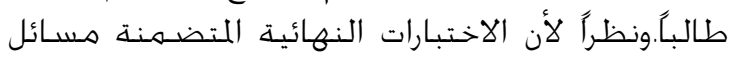

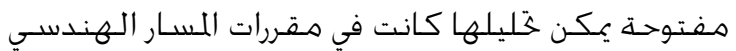

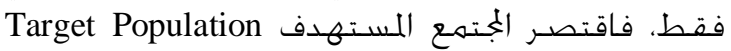

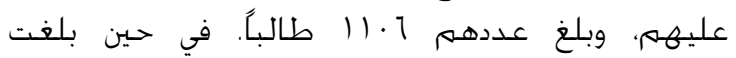

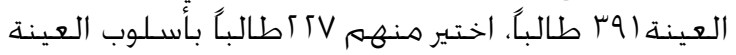
العشوائية العنقودية، حيث اختيرت · ل شعب عشوائيًاً

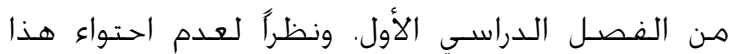

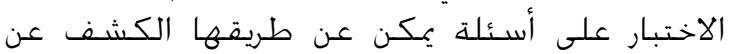

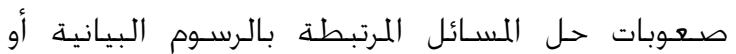

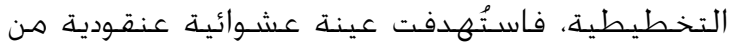

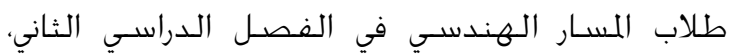

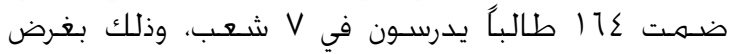

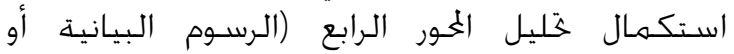

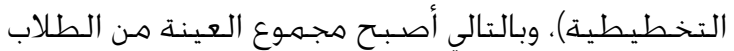

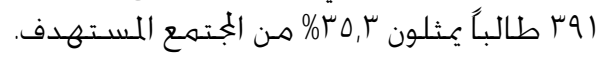

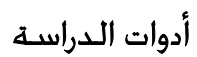

تمثلت أدوات البحث، وإجراءات صدقهها وثباتها بالتالي:

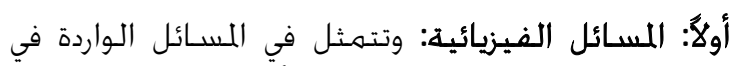

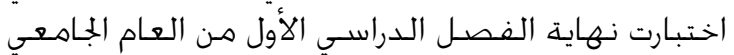

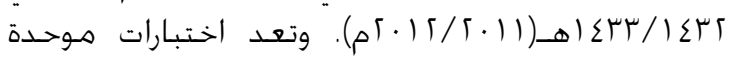

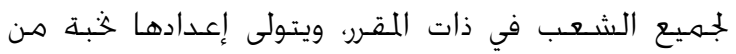

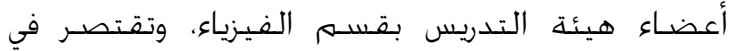

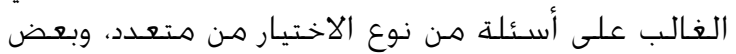

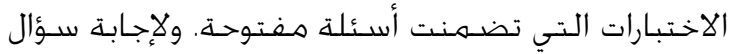

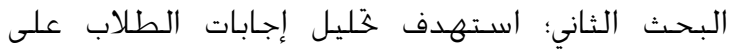

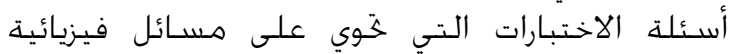

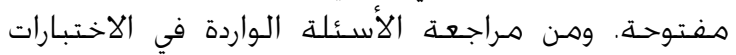

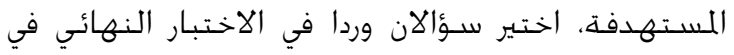

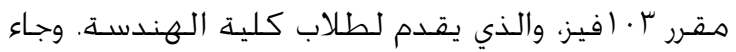

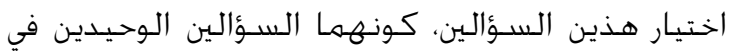

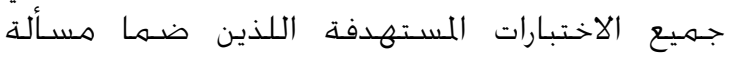

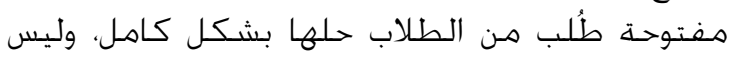

الإجابة عَنُْه فِي الامتحان" (مصطفى والزيات وعبدالقادر

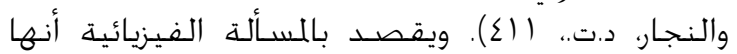
مُشكلة تتضمن بيانات فيزيائية معطاة، وتتطلب إيجاد التهاد

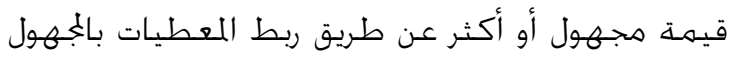

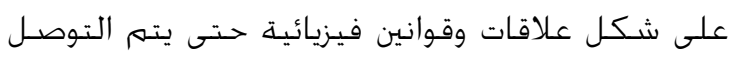

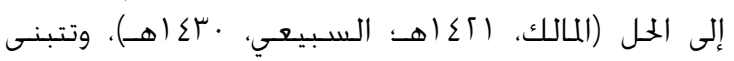

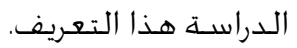
مقررات الفيزياء الأولية: مقررات الفيزياء الأولية الإجبارية

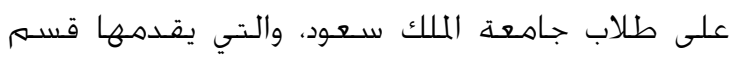
الفيزياء بكلية العلوم في جامعة الملك سعودة. وتتهثل

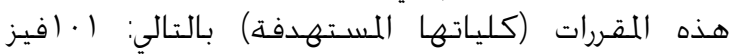

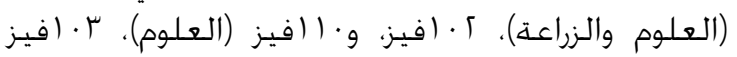

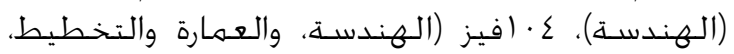

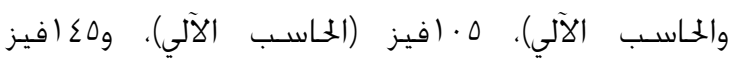
(الكليات الصحية).

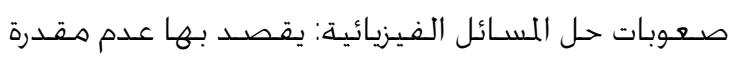

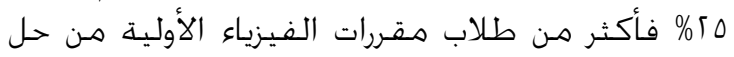

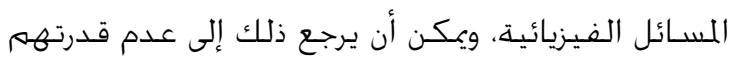

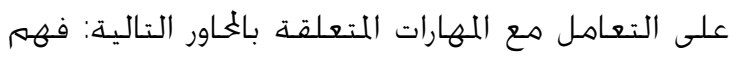

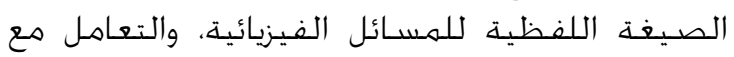
القوانين الفيزيائية، والتعامل مع المعائل المهارات الرياضية.

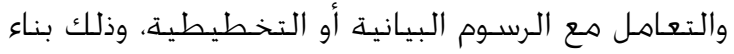

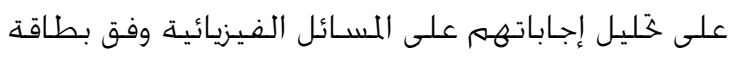

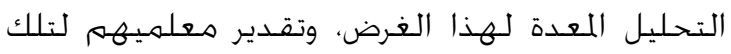

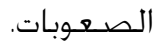

وسائل علاج صعوبات حل المسائل الفيزيائية: يقصـد

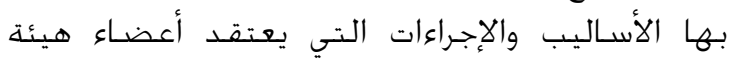

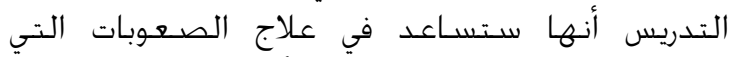
يواجهها طلاب مقررات الفيزياء الأولية عند حلـ المهات المسائل

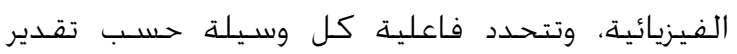

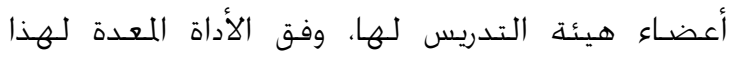

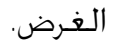

\section{الطريقة والإجراءات}

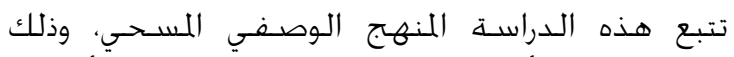

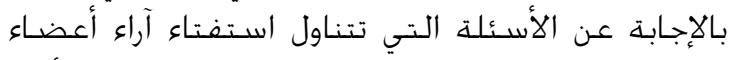

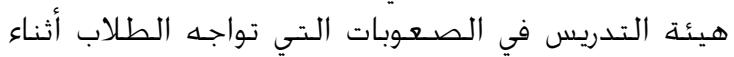

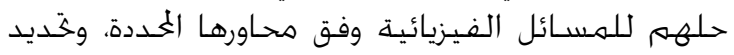

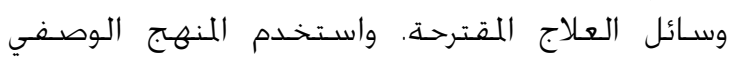

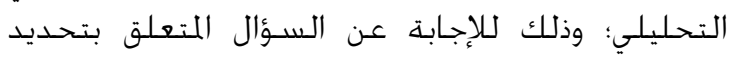

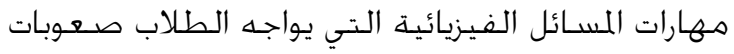

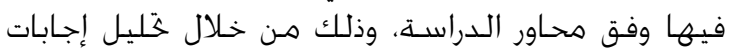
الطلاب في الاختبارات النهائية. 


\section{ثالثًا: استفتاء أعضـاء هيئة التدريس:}

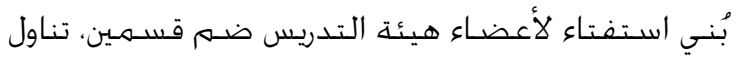

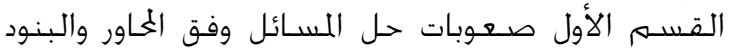

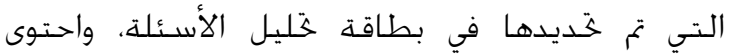

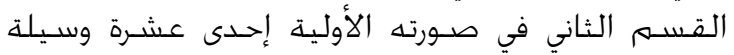

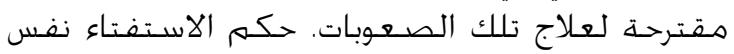

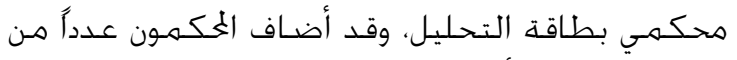
وسـائل العلاج.وأجريت بعض التحلي التعديلات الصيات الصياغية.

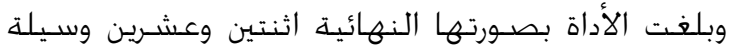

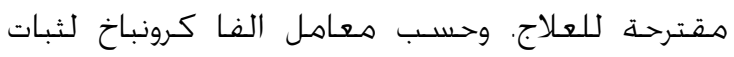
الأداة، وبلغ 917.

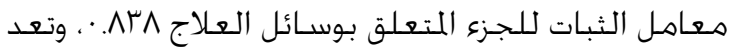
هذه الدرجات درجات ثبات مقبولة للأداة.

إجراءات جمع وخليل بيانات الدراسة اتبع الباحث الخطوات التالية في جمع بيانات دراسته

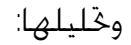

نسـق الباحث مع قسـم الفيزياء بكلية العلوم، ومكَّنه

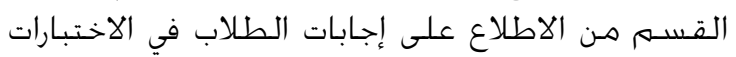

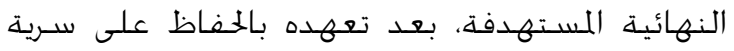

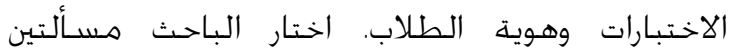

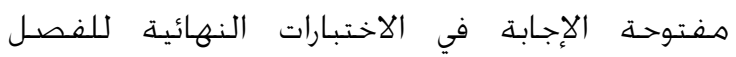

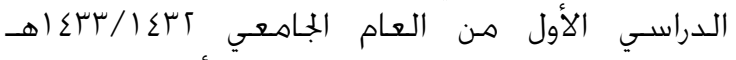

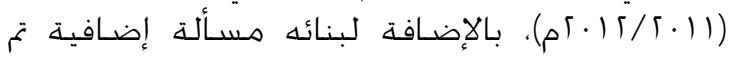

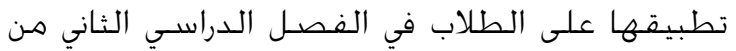

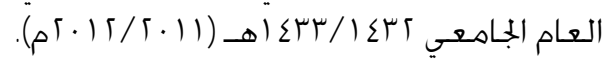

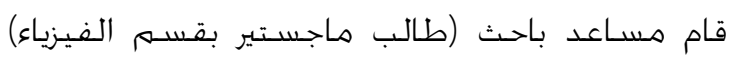

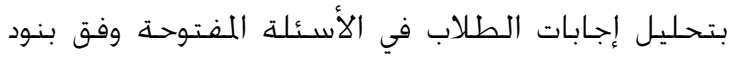
بطاقة التحليل، بعد قياس صدق الأداة وثبات التحليل.

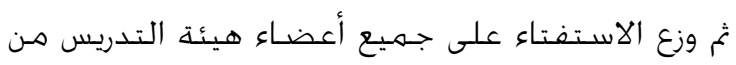

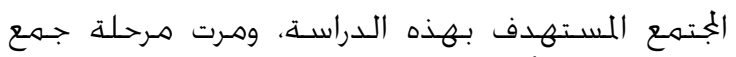

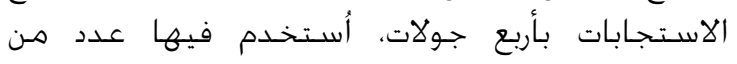

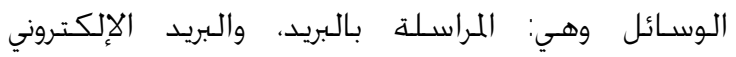

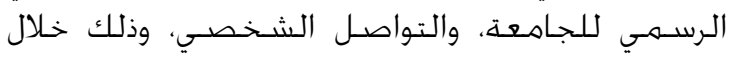

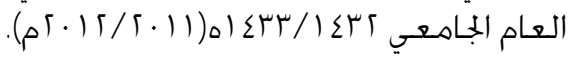

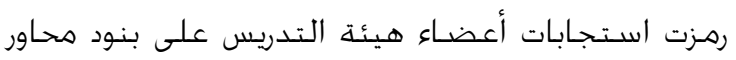

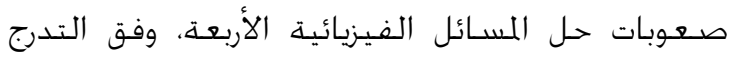

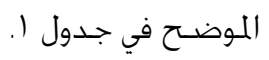

مجرد اختيار الإجابة من قائمة الاختيار من متعدد، كما

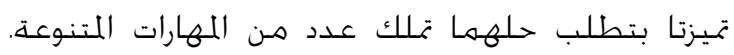

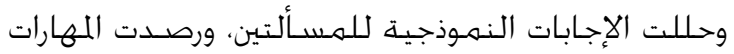

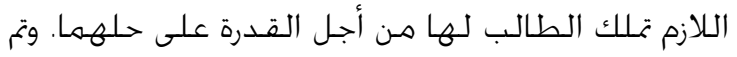
عرض ذلك التحليل على اثنين من هيئة التدريس التهاء

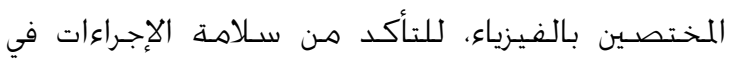

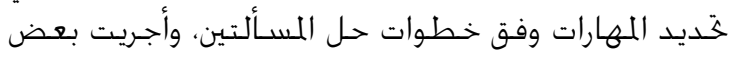
التعديلات بناء على ملاحظاتهم:

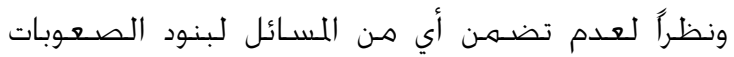

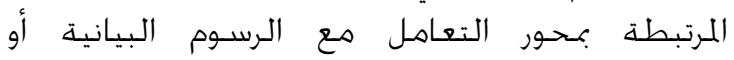

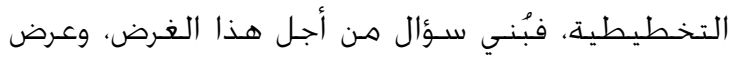

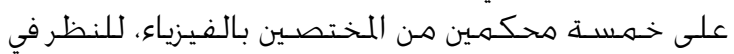

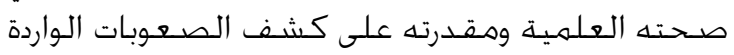

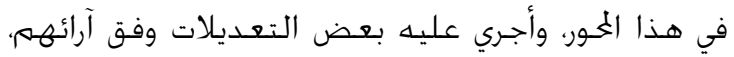

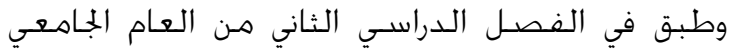

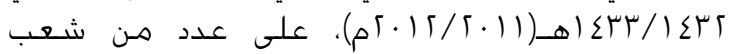

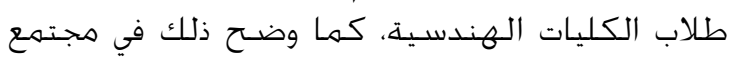

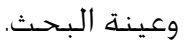

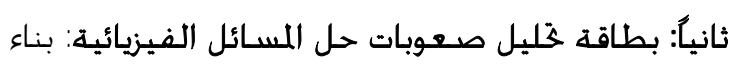

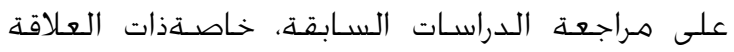

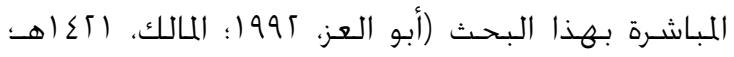

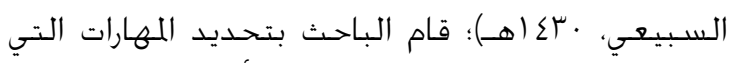

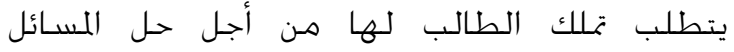

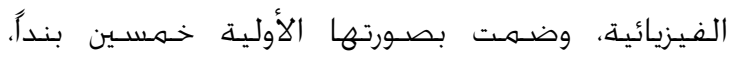

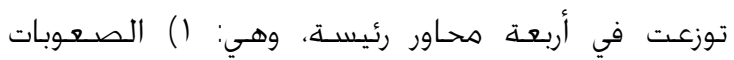

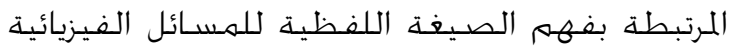

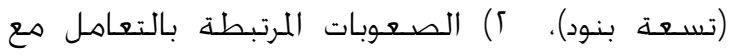
القوانين الفيزيائية (ثمانية بنود)، با) الصعونات الصعات المرتبطة

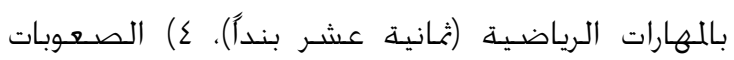

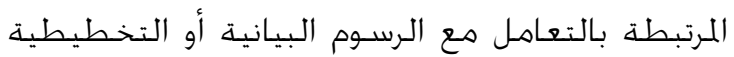

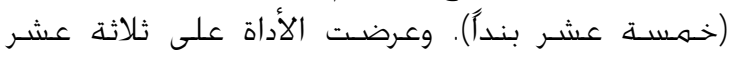

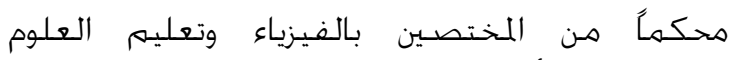

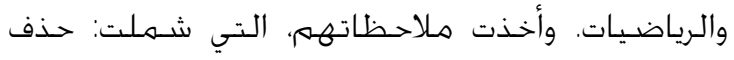

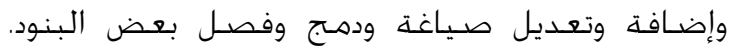

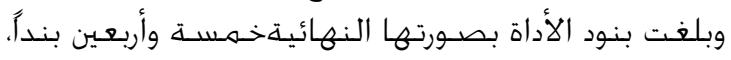

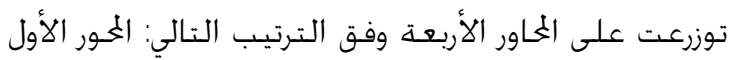

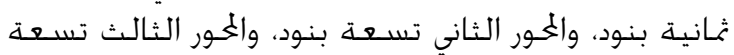

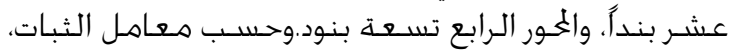

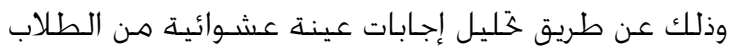

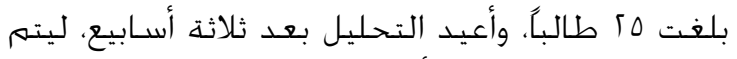

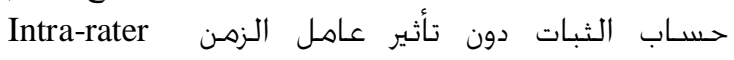

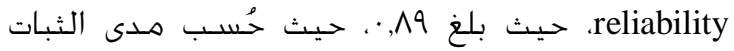

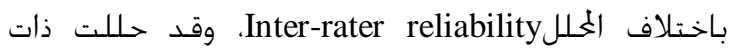
الإجابات هن مختص آخر بالفيزياء، وبلغ معامل الخافل الثبات

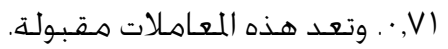




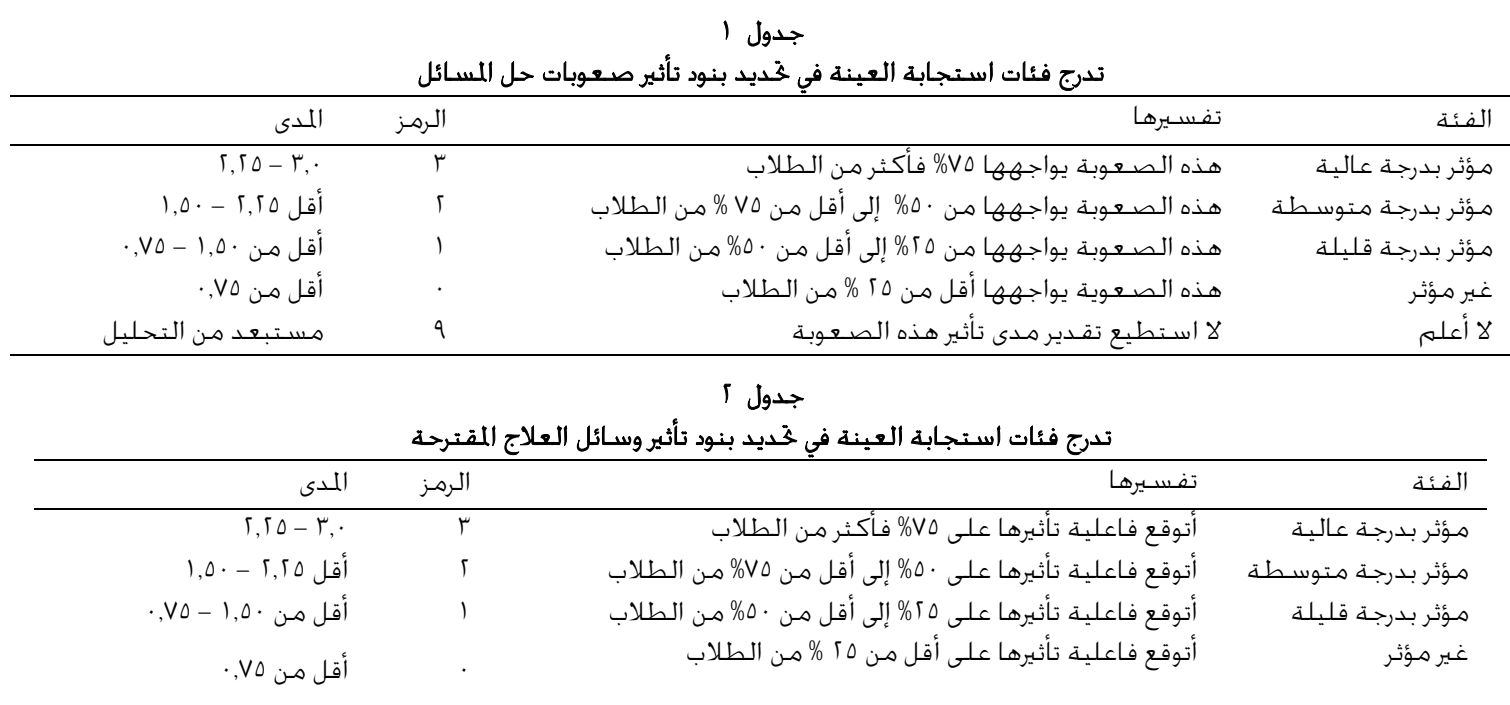

"استيعاب النص القرائي إذا كان باللغة الإجليزية"،

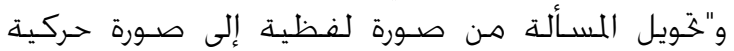

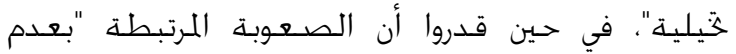
معرفة بعض المفاهيم العلمية"، مؤثرة بدرجة "قليلة".

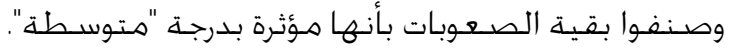

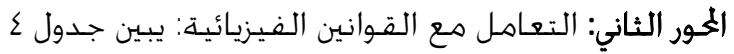

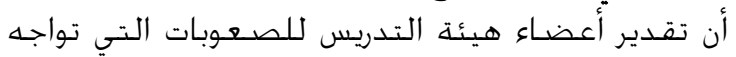

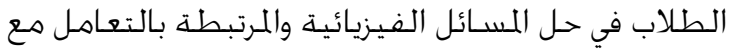

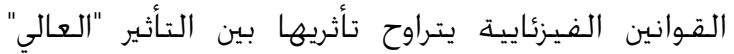

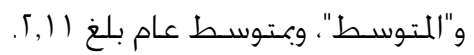

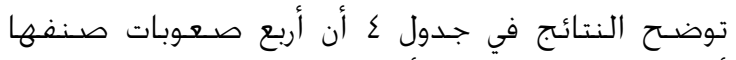

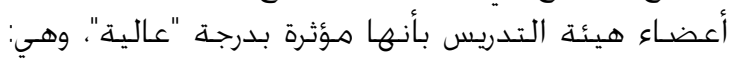

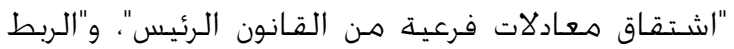

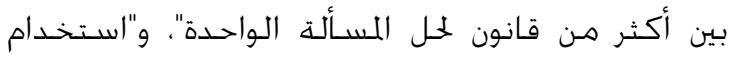

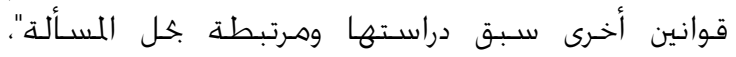

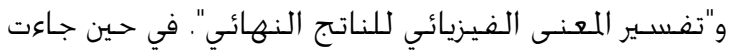

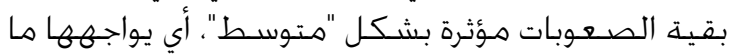

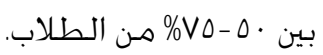

رمزت استجابات أعضاء هيئة التدريس على بنود محور

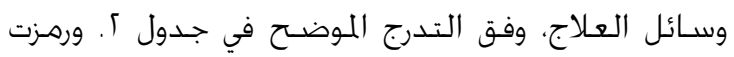

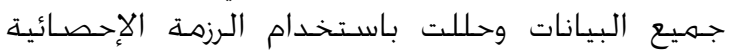

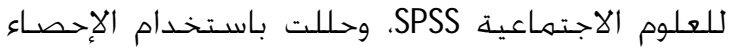

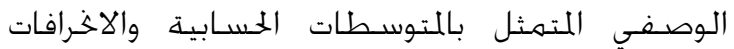

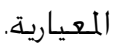

\section{النتائج}

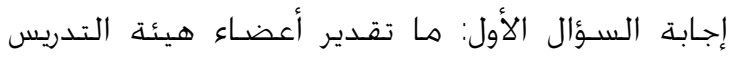

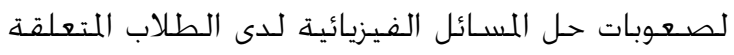

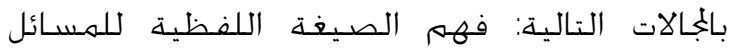
الفيزيائية، والقوانين الفيزيائية، والمهارات الرياضية،

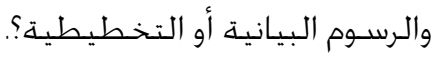

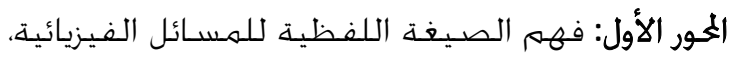

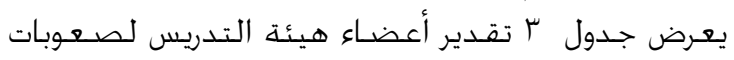

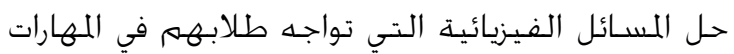
المتعلقة بفهم الصيغة اللفظية للمسالة.

توضح النتائج في جدول ب م وجود صعوبتين صنفها

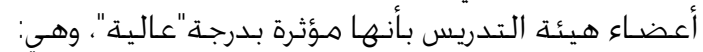

جدول

تقدير أعضاء هيئة التدريس لصعوبات حل المسائل في محور فهم الصيخة اللفظية للمسألة

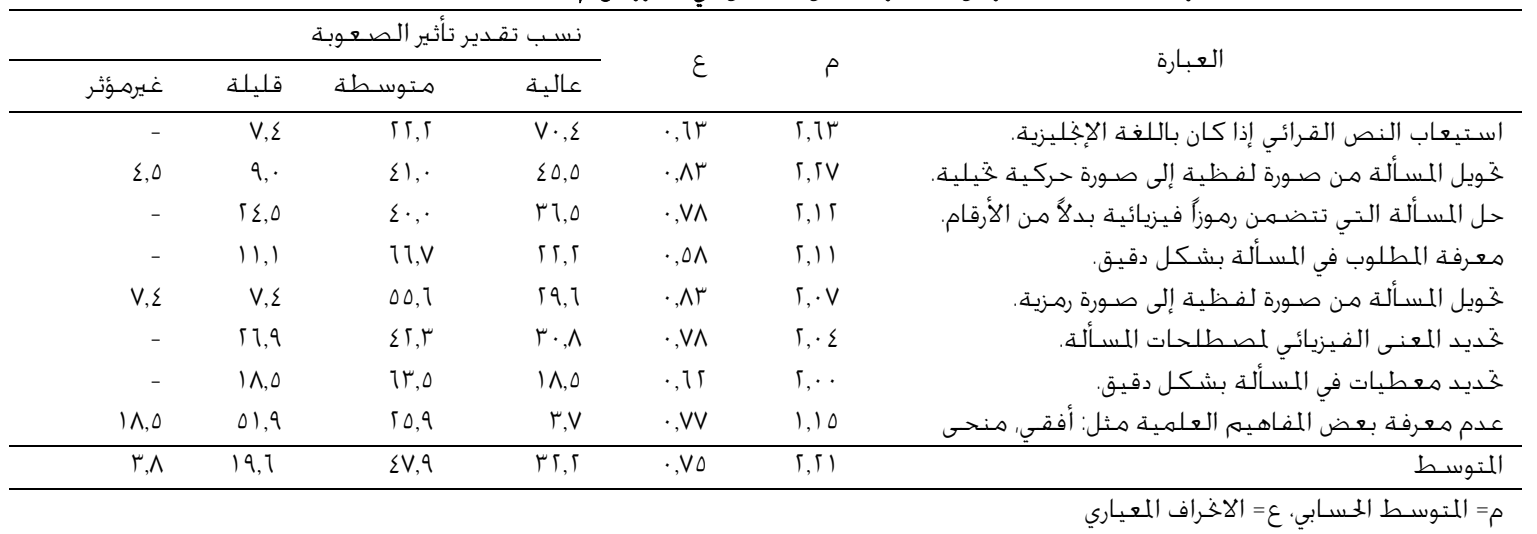


جدول

تقدير أعضـاء هبئة التدريس لصـوبات حل المسائل في محور التعامل مع القوانين الفيزيائية

\begin{tabular}{|c|c|c|c|c|c|c|}
\hline \multirow[b]{2}{*}{ غير مؤثر } & \multicolumn{3}{|c|}{ نسـب تقـدير تأثير الصــوية } & \multirow{2}{*}{$\varepsilon$} & \multirow{2}{*}{ a } & \multirow{2}{*}{ 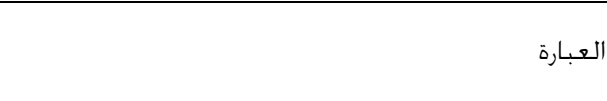 } \\
\hline & قليلة & متوسطة & عالية & & & \\
\hline- & $\mathrm{V}, \Sigma$ & 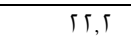 & $V \cdot, \Sigma$ & $\cdot, 1 \%$ & $\lceil, 1 \mu$ & اشتقاق معادلات فرعية من القانون الرئيس. \\
\hline- & - & $\mu r$ & $11, \mathrm{~V}$ & $\cdot, \Sigma \wedge$ & $\ulcorner, 7 \mathrm{~V}$ & الربط بين أكثر من قانون لحل المسألكة الواحـدة. \\
\hline- & $\mathrm{v}, \varepsilon$ & rV & $\Delta 0,1$ & $\cdot, 7 \pi$ & $\Gamma, \sum \wedge$ & استخـدام قوانين أخرى سبق دراستها ومرتبطة بحل المسألة. \\
\hline- & $1<, \Lambda$ & $r \mu, r$ & 01,9 & $\cdot, \mathrm{V} \varepsilon$ & $\Gamma, \mu \mathrm{V}$ & تفسير العنىى الفيزيائي للناتج النهائي. \\
\hline$r, \mathrm{~V}$ & $i t, i$ & $\Delta \Delta, 1$ & $1 \wedge, 0$ & $\cdot, \mathrm{Vo}$ & $1, \wedge 9$ & اختيار المعادلة(القانون) المناسبة لحل المسـألة. \\
\hline$r, \mathrm{~V}$ & $\lceil 9,1$ & $\varepsilon \varepsilon, \varepsilon$ & $i t, r$ & $\cdot, \Lambda\ulcorner$ & $1, \wedge 0$ & كتابة وحدة قياس الناتج النهائي بصورة صـحبحة. \\
\hline$r, \Lambda$ & $\lceil 1,9$ & 0 & 19,5 & $\cdot, \mathrm{V} \wedge$ & $1, \wedge 0$ & كتابة المعادلة المطلوبة لحل المسأَلة بصورة رهزية صحيحة. \\
\hline $\mathrm{V}, \Sigma$ & $r \mu, r$ & $\varepsilon \wedge, 1$ & 11,1 & $\cdot, \mathrm{Vq}$ & $1,7 \%$ & التعويض في المعادلة بالقيم المناسبة بطريقة صـحبحة. \\
\hline 11,0 & $r \cdot \Lambda$ & $\sum\lceil, r$ & $10, \varepsilon$ & $\cdot, 9$ & 1,11 & اختيار الثوابت الفيزيائية المناسبـة لحل المسألة. \\
\hline$r, \mu$ & 19,5 & $\varepsilon \cdot V$ & $r \uparrow, \Lambda$ & $\cdot, \mathrm{V} r$ & $\Gamma, 11$ & المتوسـ \\
\hline
\end{tabular}

جدول 0

تقدير أعضاء هيئة التدريس لصعوبات حل المسائل في محور المهارات الرياضية

\begin{tabular}{|c|c|c|c|c|c|c|}
\hline غير مؤثر & قليلة & متوسـطة & نسـب ت & $\varepsilon$ & $p$ & 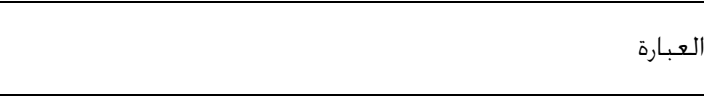 \\
\hline- & 10,2 & $\lceil 1,9$ & $\Delta V, V$ & $\cdot, \mathrm{V} 1$ & $\Gamma, \Sigma \Gamma$ & القـدرة على منطـقية التقدير الرياضـي للنتائج. \\
\hline$r, \mathrm{~V}$ & 11,1 & $\varepsilon \cdot \wedge$ & $\varepsilon \varepsilon, \Sigma$ & $\cdot, \wedge 1$ & $\lceil,\ulcorner\uparrow$ & تنفيذ العمليات الرياضـية الأسـاسية لحّل المسألة بصـورة صـحيحة. \\
\hline- & $1 \Sigma, \Lambda$ & $\Delta \Delta, 1$ & $\lceil 9,1$ & $\cdot, 11$ & $\Gamma, 10$ & حل معادلة من الدرجة الأولى في مجهولين. \\
\hline- & $i t, i$ & 01,9 & 10,9 & $\cdot, \mathrm{V})$ & $\Gamma, \varepsilon$ & ثخويل وحدات القياس من صـورة لأخرى لتوحيدها في نظام واحد. \\
\hline$r, \mathrm{~V}$ & $\lceil 9, \mathrm{~V}$ & $r \mu, r$ & $r V$, & $\cdot, 9$. & $\Gamma, \varepsilon$ & استخــام خواص التناسب في إيجاد قيمة متغير بدلاًلة متغيرات أخرى. \\
\hline $\mathrm{V}, \varepsilon$ & $1 \wedge, 0$ & $\varepsilon \varepsilon, \varepsilon$ & $\lceil 9, \mathrm{~V}$ & $\cdot, 9$. & 1,97 & التعامل مع الأسـس بطريقة صـحيحة. \\
\hline 11,0 & 19,5 & $r \cdot \wedge$ & $r \wedge, \Delta$ & $1, \cdot \varepsilon$ & 1,97 & حساب قيم الدوال المثلثية. \\
\hline- & $\mu r, r$ & $\varepsilon \cdot \wedge$ & 10,9 & $\cdot, \mathrm{V} \wedge$ & $1,9 \mu$ & إدراك الاختـاف في وحـدات القياس وضـرورة توحيدهـا في نظام واحـد. \\
\hline- & $r V$. & $r v$, & 10,9 & $\cdot, \wedge$ & $1, \wedge 9$ & حل العـادلة من الَّرجة الثانية في مجهول واحدـ. \\
\hline $1 \wedge, 0$ & $1 \varepsilon, \Lambda$ & 10,9 & $\varepsilon \cdot \Lambda$ & 1,10 & $1, \wedge 9$ & التعامل مـع الكسـور والأعداد الكســرية بشكل صــيح. \\
\hline $1 \varepsilon, \Lambda$ & $i t, 1$ & $\varepsilon \cdot, \wedge$ & $i t, i$ & $\cdot, 99$ & I,V & فك الأقواس في المقادير الحسـابية. \\
\hline$i t, i$ & $1 \varepsilon, \Lambda$ & $r \mu, r$ & $\lceil 9, \mathrm{~V}$ & $1,1 \varepsilon$ & I,V & 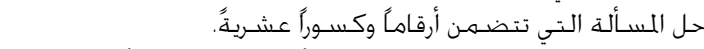 \\
\hline 11,1 & $i t, i$ & $\Delta 0,1$ & 11,1 & $\cdot, \wedge \mu$ & $1,7 \mathrm{~V}$ & تطبيق قواعد الإشـارات مع العمليات الأربع عند حل المسألة. \\
\hline 11,1 & $r \mu, r$ & $\varepsilon \cdot \wedge$ & $1 \varepsilon, \Lambda$ & $\cdot, \wedge 9$ & 1,09 & اختصـار المجهول مـن الطرفين. \\
\hline $1 \wedge, 0$ & 10,9 & $\mu r, r$ & $i t, i$ & $1, \cdot 0$ & 1,09 & تقريب الأعداد بصـورة صـيحة. \\
\hline$i t, i$ & $\mu r, \mu$ & $1 \varepsilon, \Lambda$ & $\lceil 9, \mathrm{~V}$ & 1,11 & 1,01 & حل المسألة التي تتضـمن أعداداً كبيرةً. \\
\hline$i t, i$ & $i t, 4$ & $\varepsilon \cdot, \wedge$ & $1 \varepsilon, \Lambda$ & $1, \cdot 1$ & $1, \sum \wedge$ & إيجاد قيمة الجذر بطريقة صحيحة. \\
\hline $1<, \Lambda$ & $\varepsilon \varepsilon, \varepsilon$ & $\mu r, r$ & $\mathrm{~V}, \varepsilon$ & $\cdot, \Lambda \mu$ & $1, \mu r$ & حل المعادلة مـن الدرجـة الأولى في مجهول واحـد. \\
\hline$\lceil\Lambda$ & re, & $r_{1}$. & $\varepsilon$, & $\cdot, 9$. & 1,11 & استخـدام الآلة الحاسبة عند الحلَّ بطريقة صـحيحة. \\
\hline I,V & 0,1 & $r V, V$ & $\lceil 1,9$ & $\cdot, 91$ & I,^. & المتوسـط \\
\hline
\end{tabular}

عند الحل بطريقة صـيـحة". وجاءتقدير أعضـاء هيئة

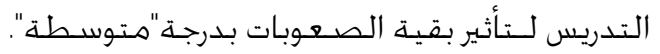
العـور الرابع: التعاهل مع الرسـوم البيانية أو التخطيطية

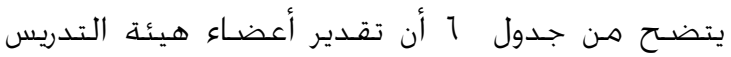

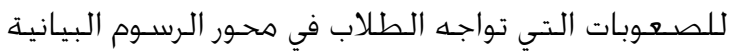

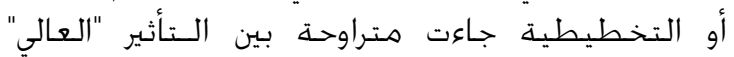
و"المتوسـط"، وبمتوسـط حسـابي بلغ · ؟, ؟.

يتبين مـن جـدول 1 وجود ثلاث صعـوبات قدر أعضـاء هيئة

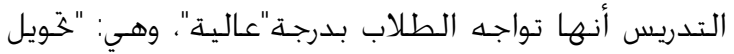

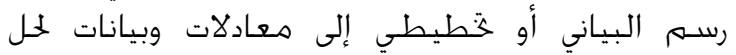

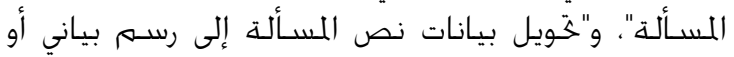

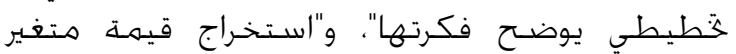

العُور الثالث: المهارات الرياضـيـة: توضـح النتائج في جـدول

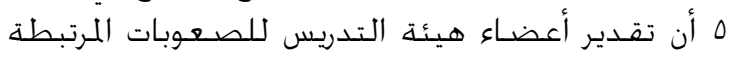

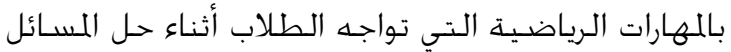

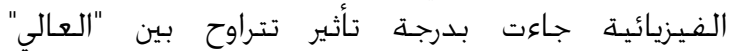

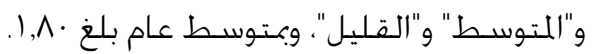

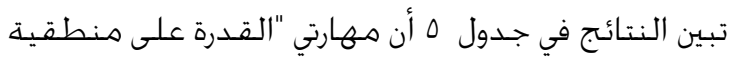

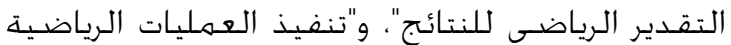

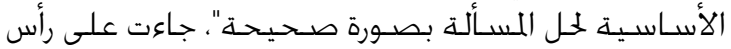

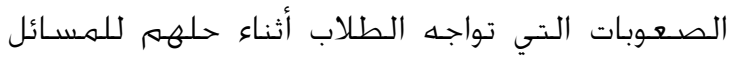
الفيزيائية، وفق تقـدير معلميهمه، وبنسبـة تأثير "عالية".

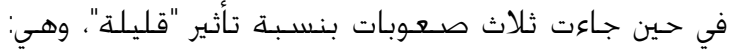

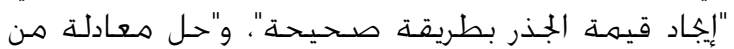

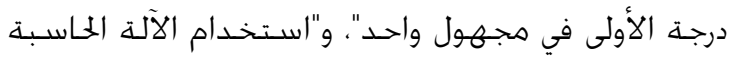


الطلاب. ولم تتح المسائل التي تم خليلها إمكانية

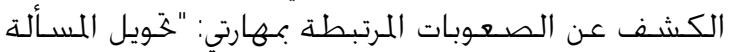

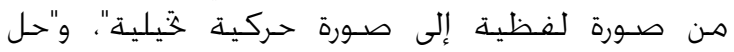
المسألة التي تتضهمن رموزاً فيزيائية بدلاً مـن الأرقام".

$$
\text { المحور الثاني: التعامل مع القوانين الفيزيائية }
$$

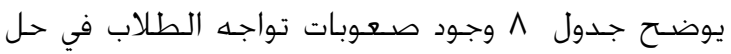
المسائل متعلقة بمحهور التعامل مع القوان بوانين الفيزيائية.

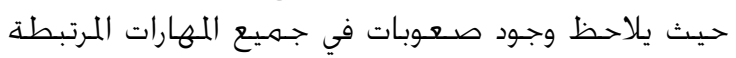

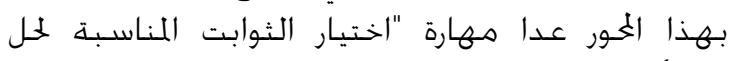

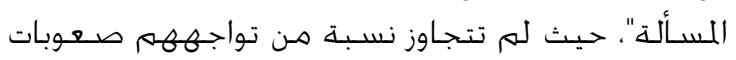
هـن الطلاب هـ\%

يتبين من جدول ^ ^ أن مهارات التعامل مع القوانين

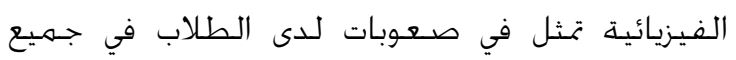

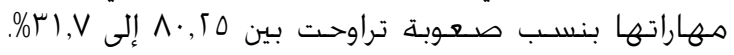

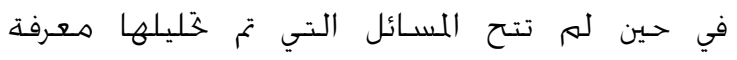
الصعوبات المرتبطة بمهارة "تفسير المعنى الفيزيائي للناتج النهائي".

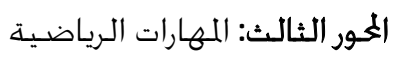

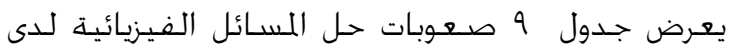

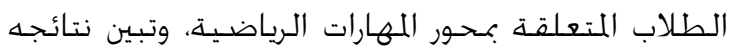

بمعرفة قيمة متغير آخـر من الرسـم". في حين صـنفوا بقية الصعوبات بأنها ذات تأثير "متوسط الرسط". في

إجابة السؤال الثاني: ها صعوبات حل المسائل الفيزيائية

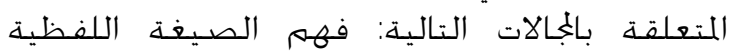

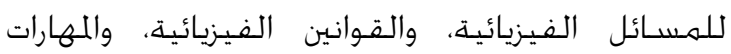

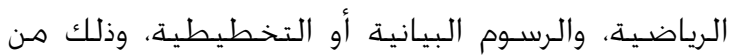
خلال ختليل إجابات الطلاب في الاختبارات النهائية؛ المحور الأول: فهم الصيغة اللفظية للمسائل الفيزيائية

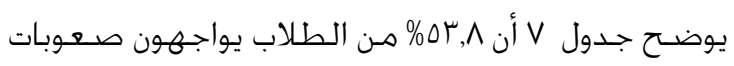

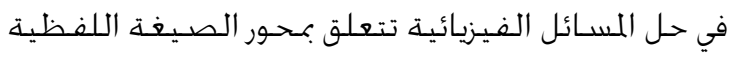

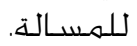

يبين جدول V أن الطلاب يواجهون صعوبات في أربع

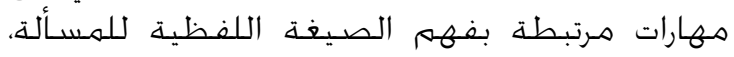

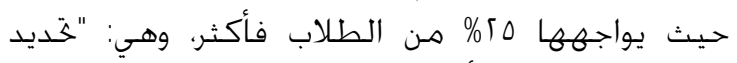
معطيات في المسألة بشكل دقياه دقيق"، و"خديد المعنى

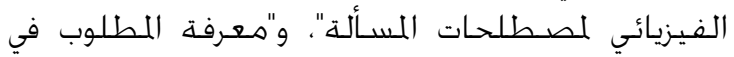

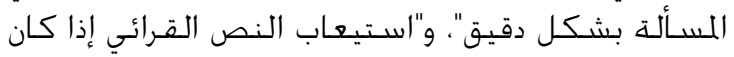

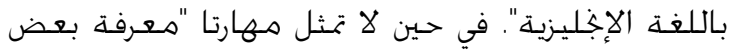

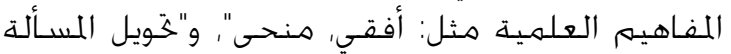

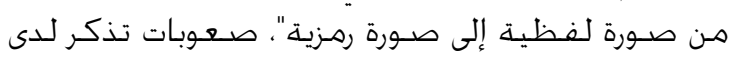

جدول 1 ج المبل في

\begin{tabular}{|c|c|c|c|c|c|c|}
\hline \multicolumn{4}{|c|}{ نسـب الاسـتجابـة } & \multirow[b]{2}{*}{$\varepsilon$} & \multirow[b]{2}{*}{ P } & \multirow{2}{*}{ 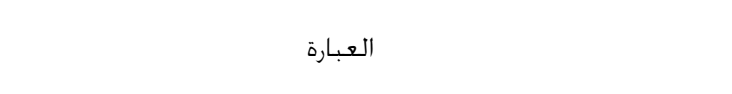 } \\
\hline غـير مؤثر & قليلة ق ق ق ق ق ق & متوسـطة & عاليـة & & & \\
\hline- & - & $\Gamma \mu, 1$ & 10,2 & $\cdot, \mathrm{VI}$ & $\Gamma, 0 \Sigma$ & 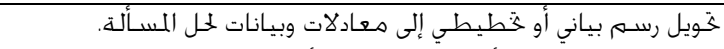 \\
\hline$r, \Lambda$ & $r, \Lambda$ & $r \cdot \Lambda$ & $\Delta V, V$ & $\cdot, \wedge 1$ & $\Gamma, \Sigma \Gamma$ & خَويل بيانات نص المسـألة إلى رسم بياني أو خُطيطي يوضـح فكرتها. \\
\hline- & - & $\Sigma 1, \Gamma$ & $\Sigma 1, \Gamma$ & $\cdot, 1 \Sigma$ & $\Gamma, \Gamma \wedge$ & اسـتخراج قيمة متغير بمعرفة قيمة متغير آخـر مـن الرسـم. \\
\hline- & - & $\Delta T$ & $r 1$ & $\cdot, 17$ & $\Gamma, \Gamma \varepsilon$ & خديديد معطيات المسـألة الفيزيائية مـن الرسـوم البيانية أو التخـطيطية. \\
\hline- & - & $\sum \wedge$ & $r 1$ & $\cdot, \mathrm{V})$ & $\ulcorner, \Gamma \cdot$ & خدـيـد مقيـاس الرسم المناسـب. \\
\hline$\varepsilon$ & $\Sigma$ & $\Delta 1$ & re & $\cdot, \mathrm{V} \Delta$ & $\lceil, 11$ & التميـيز بين المتغير التابع والمسـتقـل في الرسـوم البيانية. \\
\hline$r, \Lambda$ & $r, \wedge$ & $\Delta$ & $r \varepsilon, 1$ & $\cdot, \mathrm{V} \wedge$ & 5,10 & خدـيد العـلاقات بين المتغـيرات في الرسـمهم البياني. \\
\hline$r, \Lambda$ & $r, \Lambda$ & $\Delta r, 9$ & $\lceil 1,9$ & $\cdot, \mathrm{VV}$ & $\Gamma, \varepsilon$ & خديديد مسـميات الإحـداثيات من المسألة وفقاً لطبيعة المتغيرات. \\
\hline 11,1 & 11,1 & $\Sigma \varepsilon, \Sigma$ & $1 \Sigma, \Lambda$ & $\cdot, \wedge \wedge$ & $1,7 \mu$ & إيجاد قيمة ميل الخط المستقيم. \\
\hline$\Gamma, 9$ & $\Gamma, 9$ & $\varepsilon \varepsilon, 9$ & $r \Lambda, \Lambda$ & $\cdot, \mathrm{V} \Delta$ & $\ulcorner, \Gamma \cdot$ & المتوسـط \\
\hline
\end{tabular}

تقدير أعضاء هيئة التدريس لصعوبات حل المسائل في محور الرسوم البيانبة أو التخطيطية

جدول

م= المتوسط الحسابي، ع= الاخراف العياري

\begin{tabular}{|c|c|c|c|c|c|c|c|}
\hline \multicolumn{2}{|c|}{ لا يمكن الخكم } & \multicolumn{2}{|c|}{ لا توجد صعوبة } & \multicolumn{2}{|c|}{ توجد صعوبة } & \multirow{2}{*}{ 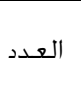 } & \multirow{2}{*}{ الصــوية } \\
\hline$\%$ & ت & $\%$ & ت & $\%$ & ت & & \\
\hline$\cdot, \Sigma$ & 1 & $\varepsilon, \Lambda$ & 11 & $9 \varepsilon, V$ & $\lceil 10$ & itV & تحديد معطيـات في المسـألة بشكل دقيق. \\
\hline$\cdot, \Sigma$ & 1 & $15, r$ & $\lceil\wedge$ & $\Lambda \vee, r$ & 191 & ite & تحديد اللعنى الفيزيائي للصطبلحات المسألة. \\
\hline- & - & $\varepsilon \varepsilon, 9$ & $1 \cdot 5$ & $\Delta \Delta, 1$ & 150 & ite & معرفة اللطلوب في المسـألة بشكل دقيق. \\
\hline- & - & $\varepsilon \wedge$. & $1 \cdot 9$ & $\Delta T$ & 111 & ite & اســيعاب النص القُرائي إذا كان باللغة الإبخليزية. \\
\hline 「, Г & 0 & $V \varepsilon, 1$ & $17 \mathrm{~V}$ & $\lceil\varepsilon, 1$ & $\Delta \Delta$ & ite & عدم معرفة بعض المفاهيم العلمية مثل: أفقي, منحى,... \\
\hline$\cdot, \Sigma$ & 1 & $9 \cdot, r$ & $r \cdot 0$ & $9, r$ & $\lceil 1$ & ite & خَويل المسـألة مـن صـورة لفظظية إلى صـورة رمزية. \\
\hline$\cdot, 1$ & r & $\varepsilon 0, \wedge$ & $1 \cdot r$ & $\Delta \varepsilon, \Gamma$ & 151 & itr & المتوسـط \\
\hline $1 \ldots$ & tiv & - & - & - & - & itV & خويل المسألة من صورة لفظية إلى صورة حركية خَيلية. \\
\hline $1 \cdots$ & itV & - & - & - & - & ite & حل المسألة التي تتضـمن رموزًا فيزيائية بدخً من الأرقام. \\
\hline
\end{tabular}

صـوبات حل المسائل في محور الصيغة اللفظية للمسائل الفيزيائية 


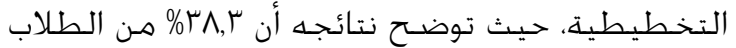
يواجهون صعوبات في بعض المهارات المرتبطة بهذا المهور.

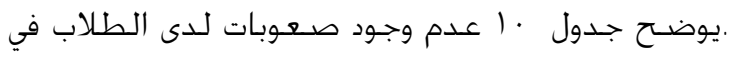

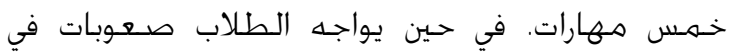

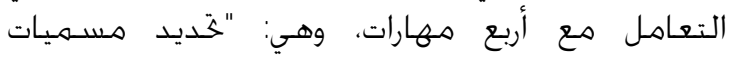

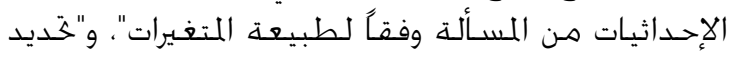

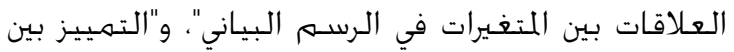

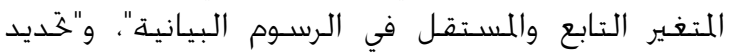
مقياس الرسـم المناسبـ".

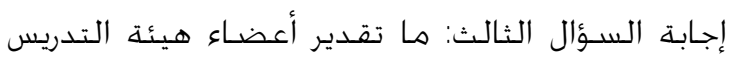

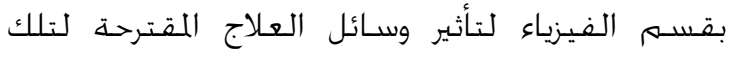

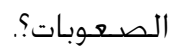

وجـود صعوبات لدى الطلاب في مهارتين فقط هـما:

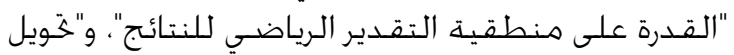

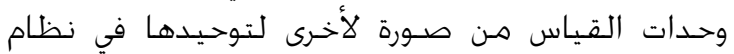
واحـد". يوضسح جدول و أن الطلاب لا يعانون مـن صعوبات في

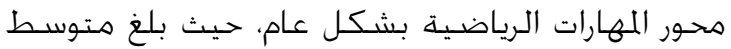

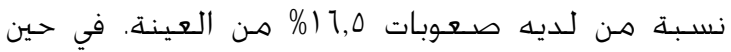

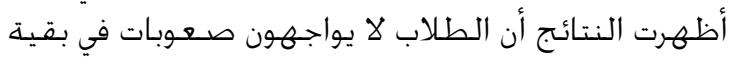

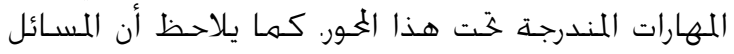

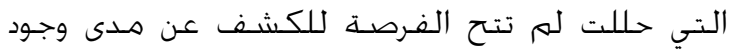
صعوبات سـت مهارات.

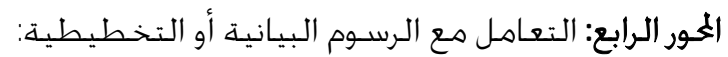

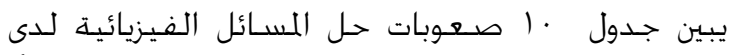

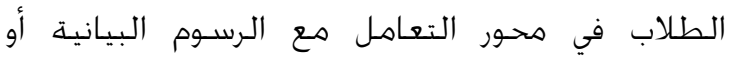

جدول $\wedge$

صعوبات حل المسائل في محور التعامل مع القوانين الفيزيائية

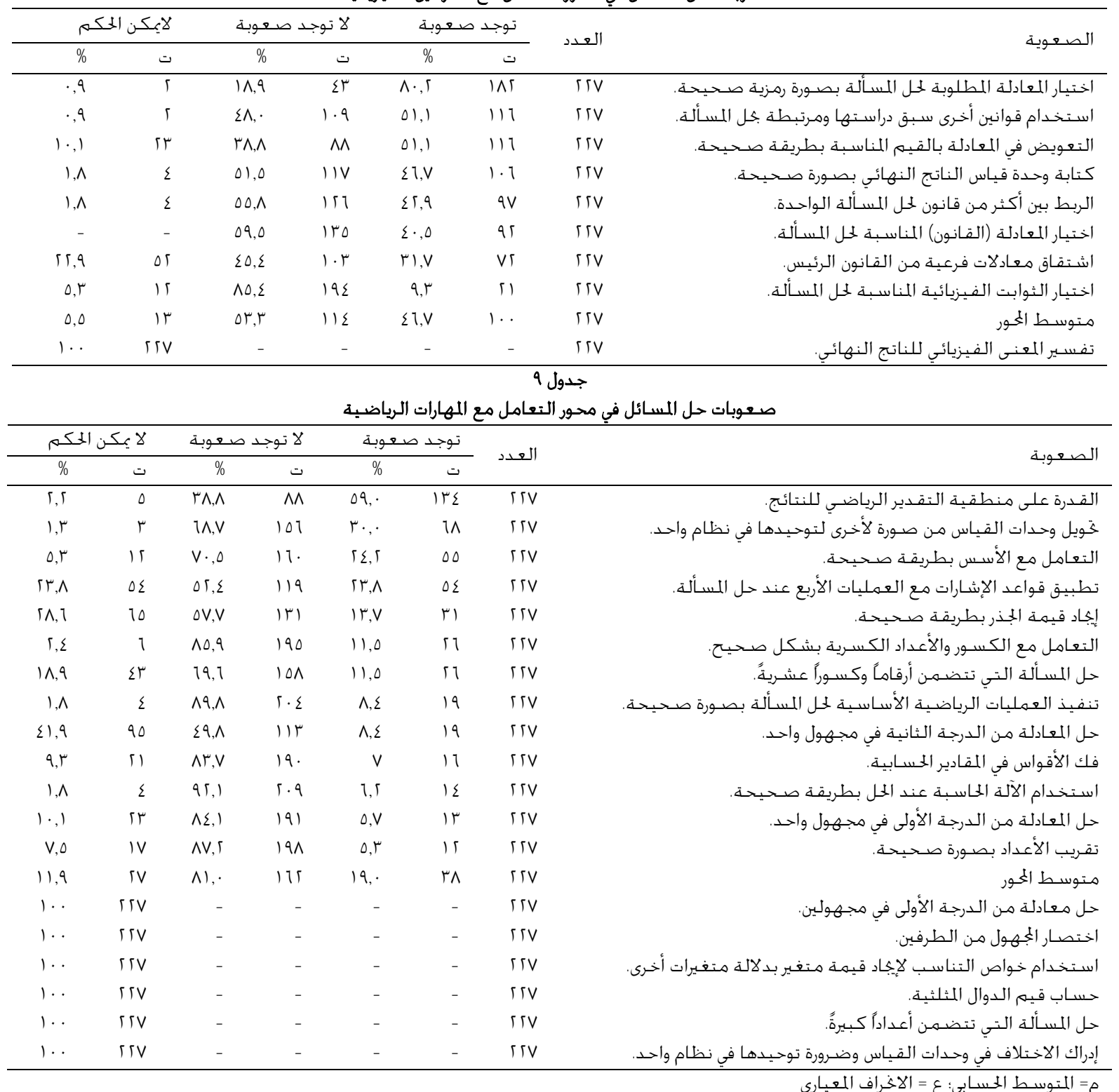


جدول ·

صعوبات حل المسائل في محهور التعامل مع الرسـوم البيانية أو التخطبطية

\begin{tabular}{|c|c|c|c|c|c|c|c|}
\hline \multicolumn{2}{|c|}{ لايمكن الخكم } & \multicolumn{2}{|c|}{ لا توجد صـوبة } & \multicolumn{2}{|c|}{ توجد صعوبة } & \multirow{2}{*}{ 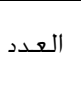 } & \multirow{2}{*}{ 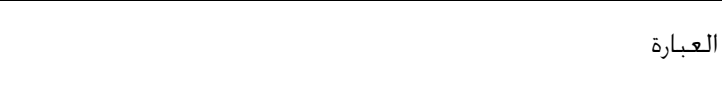 } \\
\hline$\%$ & ت & $\%$ & $ت$ & $\%$ & ت & & \\
\hline- & - & $r, \mathrm{~V}$ & 1 & $97, r$ & 101 & $17 \varepsilon$ & خَديد مسـميات الإحـداثيات من المسألة وفقاً لطبـعة المتغيرات. \\
\hline- & - & $\mathrm{V}, \mathrm{r}$ & 11 & $9 \Gamma, V$ & 105 & $17 \varepsilon$ & خديد العلاقات بين المتغيرات في الرسمع البياني. \\
\hline- & - & rq & $1 \varepsilon$ & 11,0 & $1 \cdots$ & $17 \varepsilon$ & التمييز بين المتغير التابع والمسـتِقل في الرسـوم البيانية. \\
\hline- & - & $\mathrm{V} \cdot \mathrm{V}$ & 117 & $19, r$ & $\Sigma \wedge$ & $17 \varepsilon$ & 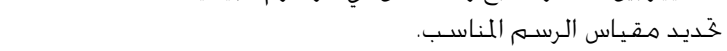 \\
\hline- & - & $\Lambda \cdot, 0$ & $1 \%$ & 19,0 & re & $17 \varepsilon$ & اسـتخراج قيمة متغير بمعرفة قيمة متغير آخر من الرسـم. \\
\hline- & - & $\Lambda r, 0$ & $1 \mu \mathrm{V}$ & 17,0 & iv & $17 \varepsilon$ & خديد معطيات المسألة الفيزيائية من الرسـوم البيانية أو التخطيطية. \\
\hline- & - & $\wedge 1,1$ & $1 \leqslant 5$ & $1 \%, \Sigma$ & it & $17 \varepsilon$ & خويل بيانات نص المسألة إلى رسـم بياني أو خَطيطي يوضح فكرتها. \\
\hline- & - & $\wedge 9,0$ & 10 & $\Lambda, 0$ & $1 \varepsilon$ & $17 \varepsilon$ & إيجاد قيمة ميل الخط المستقيم. \\
\hline- & - & $95, \mathrm{~V}$ & 105 & $\mathrm{~V}, r$ & 15 & $17 \varepsilon$ & خويل الرسـم البياني أو التخطيطي إلى معادلات وبيانات لحل المسألة. \\
\hline- & - & 71,0 & $1 \cdot 1$ & $r \wedge, r$ & 14 & $11 \varepsilon$ & متوسـط المهور \\
\hline
\end{tabular}

جدول 11

م= المتوسط الحسبابي: ع = الاخراف المعياري

تقدير أعضاء هيئة التدريس لتأثير وسائل علاج صعوبات حل المسائل الفيزيائية

\begin{tabular}{|c|c|c|c|c|c|}
\hline \multicolumn{4}{|c|}{ تقـدير نسـبـة تاثير الوسـيلة } & \multirow{2}{*}{$\varepsilon$} & \multirow{2}{*}{ a } \\
\hline غـير مؤثر & قليلة & متوسـطة & عاليـة & & \\
\hline- & $r, \mathrm{~V}$ & $\mathrm{~V}, \Sigma$ & $\wedge \wedge, 9$ & $\cdot, \Sigma 01$ & $\Gamma, \wedge 0$ \\
\hline- & - & $1 \Sigma, \wedge$ & $\wedge \Delta, \Gamma$ & $\cdot, \mu 1 \Gamma$ & $\lceil, \wedge \Delta$ \\
\hline- & - & $1 \Sigma, \wedge$ & $\wedge \Delta, \Gamma$ & ז & $\lceil, \wedge \Delta$ \\
\hline- & r,V & 11,1 & $\wedge \Delta, \Gamma$ & $\cdot, \Sigma \wedge r$ & $\lceil, \wedge)$ \\
\hline- & $\mathrm{V}, \Sigma$ & 11,1 & $\wedge 1,0$ & $\cdot, 09 \varepsilon$ & $\Gamma, V \varepsilon$ \\
\hline$r, \mathrm{~V}$ & $\mathrm{~V}, \varepsilon$ & 11,1 & $V V, \wedge$ & $\cdot, \mathrm{V} 9 \mathrm{~T}$ & $\Gamma, 1 \Gamma$ \\
\hline- & $\mathrm{V}, \Sigma$ & $\lceil\uparrow, \uparrow$ & $V \cdot, \Sigma$ & $\cdot, 119$ & $\Gamma, 1 \mu$ \\
\hline- & $1 \Sigma, \wedge$ & $\lceil 9,1$ & $\Delta \Delta, 1$ & $\cdot, \mathrm{V} \leqslant \mathrm{V}$ & $\lceil, \Sigma)$ \\
\hline- & $r, \mathrm{~V}$ & 01,9 & $\varepsilon \Sigma, \Sigma$ & $\cdot, \mathrm{V} \leqslant \mathrm{V}$ & $\lceil, \Sigma)$ \\
\hline r,v & $\mathrm{V}, \Sigma$ & $\mu r$ & $\Delta \Delta, 1$ & $\cdot, \mathrm{V} 9 \mathrm{~V}$ & $\lceil, \Sigma\rceil$ \\
\hline- & 11,1 & $\Sigma \Sigma, \Sigma$ & $\Sigma \Sigma, \Sigma$ & $\cdot, 1 \vee 9$ & $\Gamma, \mu r$ \\
\hline r,v & 11,1 & rV & $\sum \wedge, 1$ & $\cdot, \wedge \uparrow \Psi^{\mu}$ & $\Gamma, \Gamma$. \\
\hline r,v & $\mathrm{V}, \Sigma$ & $\Sigma \varepsilon, \Sigma$ & $\varepsilon \varepsilon, \varepsilon$ & $\cdot, \mathrm{VV} \Delta$ & $\Gamma, \Gamma$. \\
\hline$r, \Lambda$ & $r, \Lambda$ & $\Delta H_{, \Lambda}$ & $r \wedge, 0$ & $\cdot, \mathrm{V}\lceil\Sigma$ & I, IV \\
\hline r.V & $\mathrm{V}, \Sigma$ & $\sum \wedge, 1$ & $\varepsilon \cdot, V$ & $\cdot, \mathrm{V} \backslash \Sigma$ & $\lceil, \Gamma]$ \\
\hline$r, \Lambda$ & 11,0 & $\sum 1, r$ & $r \wedge, \Delta$ & $\cdot, \wedge \cdot 1$ & 1,19 \\
\hline 11,1 & 11,1 & $\lceil 0,9$ & 01,9 & $1, \cdot \varepsilon$ & 1,19 \\
\hline $\mathrm{V}, \mathrm{L}$ & 11,1 & $\sum \wedge, 1$ & $r \mu, r$ & $\cdot, \wedge \vee \varepsilon$ & $\Gamma, \cdot V$ \\
\hline$V, \Sigma$ & $\lceil\Gamma, \Gamma$ & $\sum \Lambda, 1$ & $\lceil\Gamma, \Gamma$ & $\cdot, \wedge 1 \Sigma$ & $1, \wedge \Delta$ \\
\hline rT & $\mu \cdot \Lambda$ & 10,2 & $\mu \cdot, \Lambda$ & $1, I V$ & $1,0 \Sigma$ \\
\hline$r, \Lambda$ & $\Sigma 1, \Gamma$ & $\Sigma 1, r$ & $r, \Lambda$ & $1, \Sigma 1$ & 1,0 \\
\hline 19,7 & 10,9 & $\lceil\Gamma, \Gamma$ & एT, & 1,10 & $1, \mu \mathrm{V}$ \\
\hline
\end{tabular}

تمكن الطلاب من المهارات الأسـاسية للرياضيات في السنة التحضيرية.

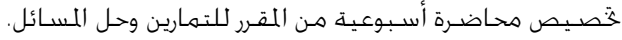

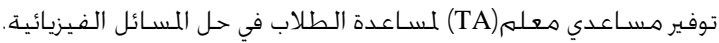
تعزيز قدرات الطلاب باللغة الإبخليزية في السـنة التحضيرية.

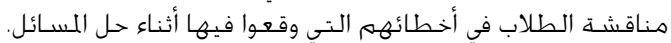
رفع المستوى اللغوي لدى الطلاب.

التدريب على حل المسائل الفيزيائية بالواجبات والتكليفات المنابل المنزلية.

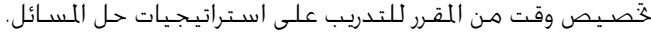

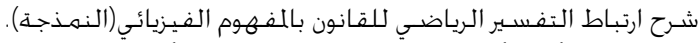

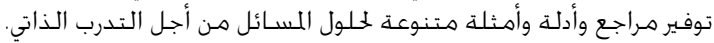

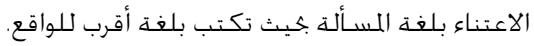
تنمية مهارات حل المسائل، مثل: توقع الإجابة قبل الحل والتح والتأكد بعده.

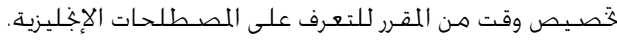

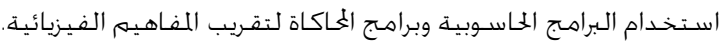

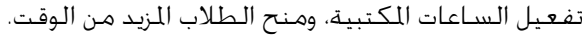

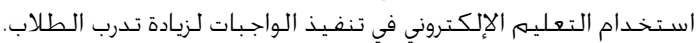

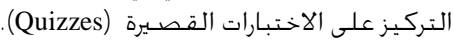

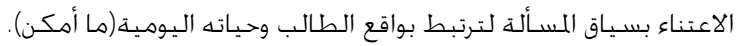

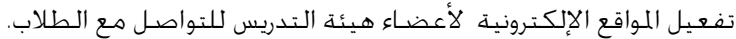

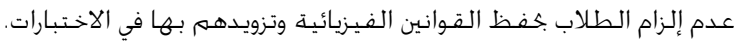

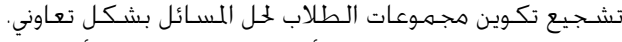

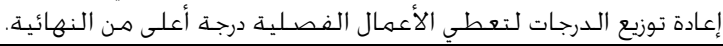

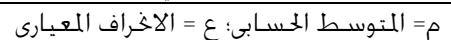

و"تعزيز قدرات الطلاب باللغة الإجنليزية في السـنة

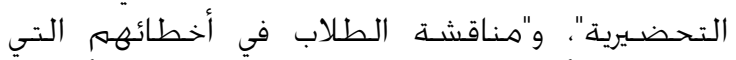

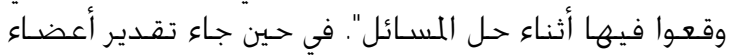

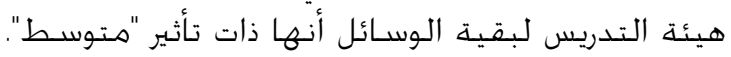

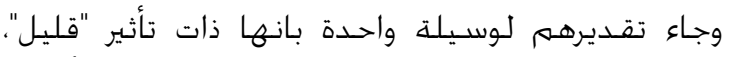
وهي:"إعادة النظر في توزيع الدرجات لتعطى للـألعهمال الفصلية درجـة أعلى مـن النهائية".

\section{مناقشـة النتائج}

هدفت هذه الدراسـة إلى خدّيد الصـــوبات التي يواجهها

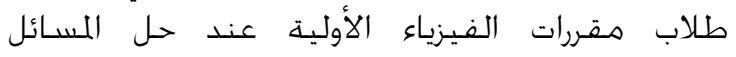

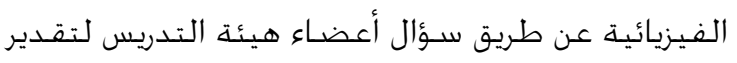

يوضسح جـدول ال التقدير أعضـاء هيئة التدريس لدرجـة

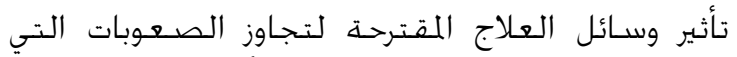

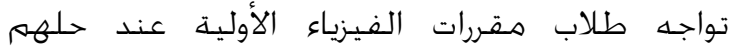
للمسـائل الفيزيائية.

يتضح هـن جدول ال أن تقدير أعضـاء هيئة التدريس

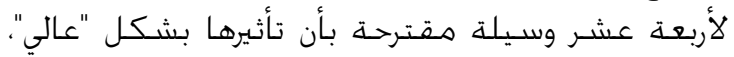

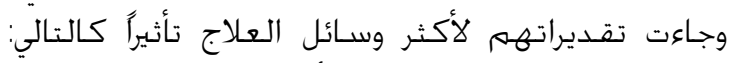

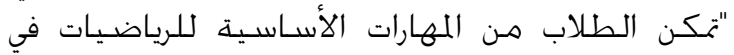

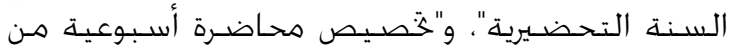

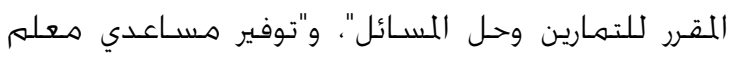
لمسـاعدة الطلاب في حل المسائل الفيزيائية"، 
إن عناية أعضاء هيئة التدريس في صياغة المسألة

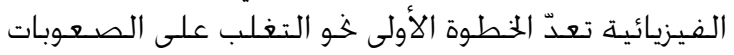

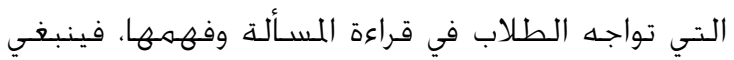

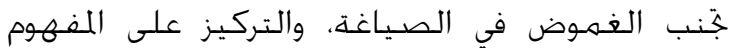

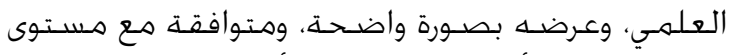

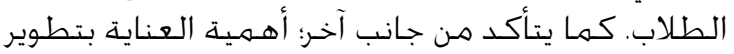

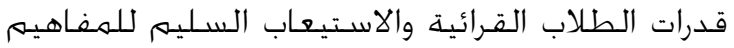

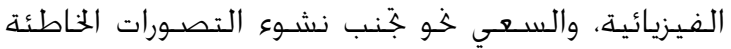

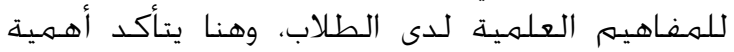

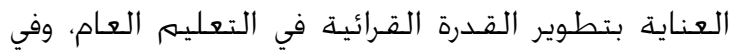

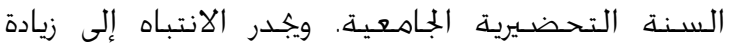
الاهتمام بتطوير قدرات الطلاب في اللغة الإبجليزية.

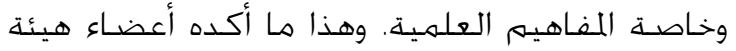
التدريس في وسائل العلاج التي يرون تأثيرها، حيث جاءئ أعاءت العاءت

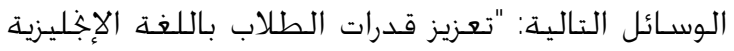

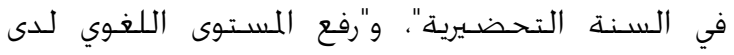

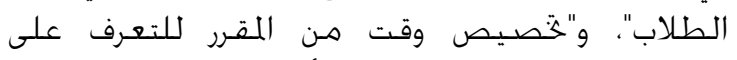

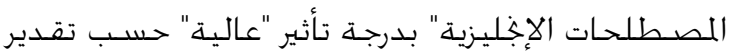

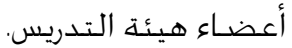

كما أن تكثيف حل المسائل قد يعطي أثره في هذا الجمال،

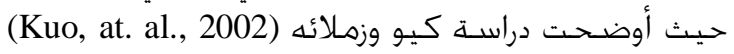

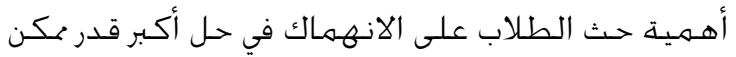
من المسائل، وذلك عن طريق الاختبارات والواجبات المناء المزلية.

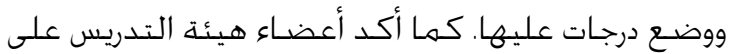
فاعلية "ختصيص محاضـرة أسبوعية من المقرر للتمارين.

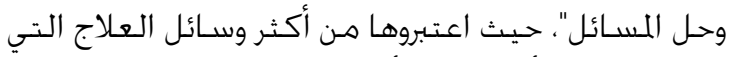
يتوقعون جاح تأثيرها على أكثر من ه/ /\% من الطلاب.

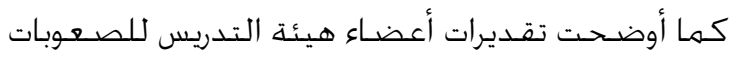

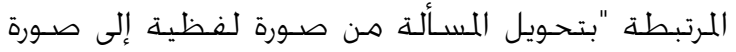

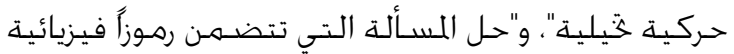

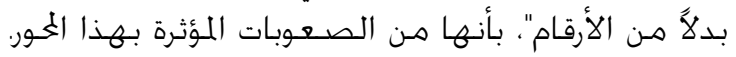

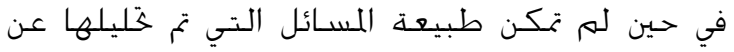

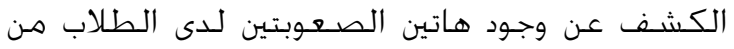

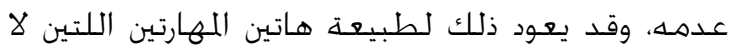

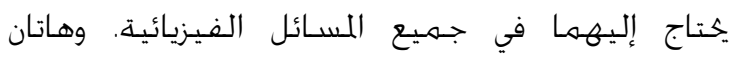

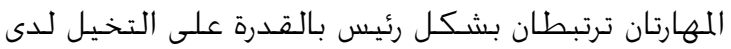

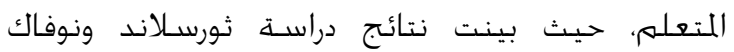
(Thorsland \& Novak, 1972) القدرة التخمينة والتحليلية من أجل حل المسألة المهين الفيزيائية.

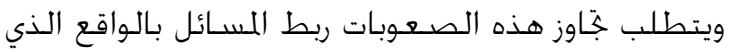

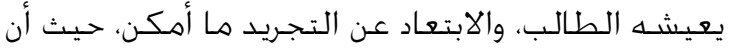

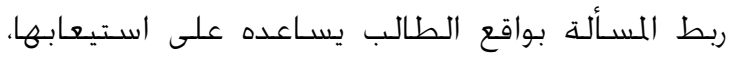

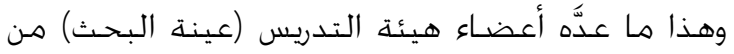

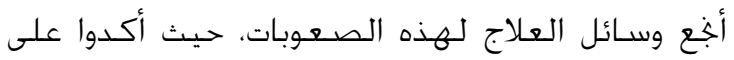

تلك الصعوبات، وكذلك عن طريق خحليل إجابات الطلاب على المسائل الفيزيائية الواردة في الاختبارات النهائيات النيائية.

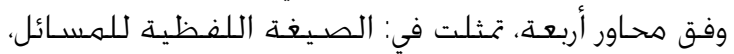

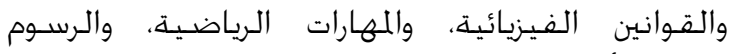

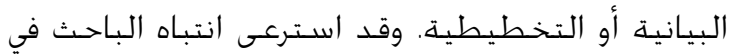

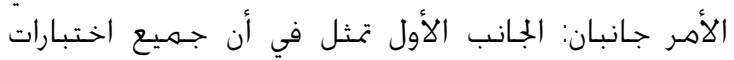

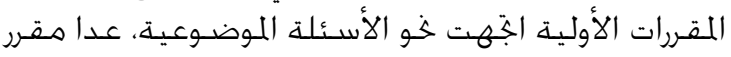

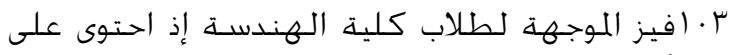

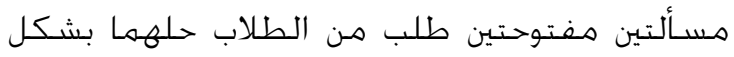

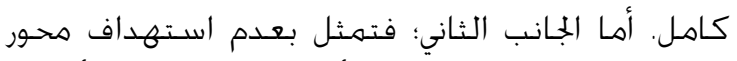

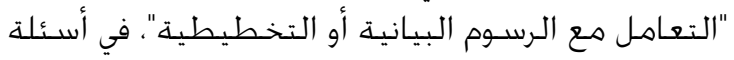

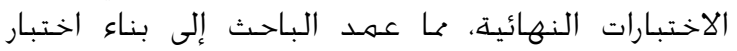

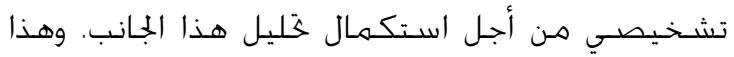

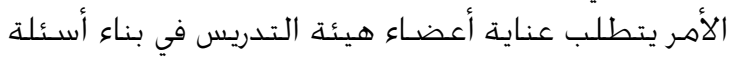

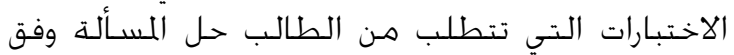

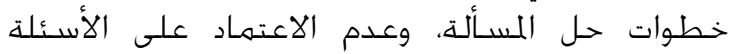

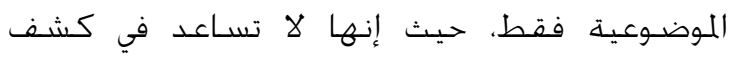

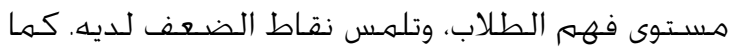

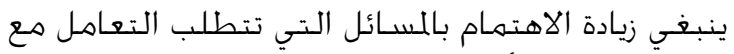

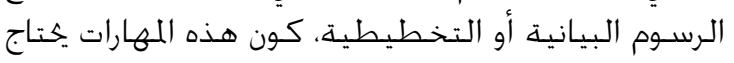

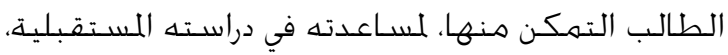

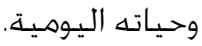

توضح النتائج توافق نتائج خَليل إجابات الطلابعلى

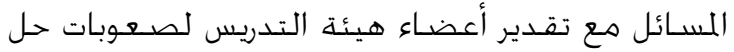

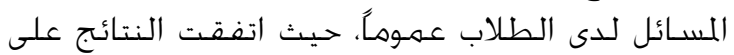

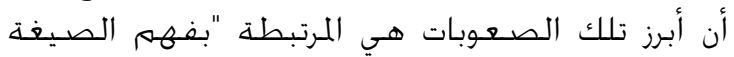

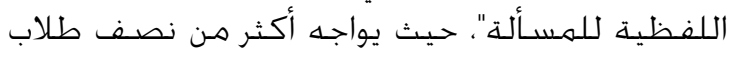

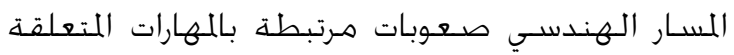

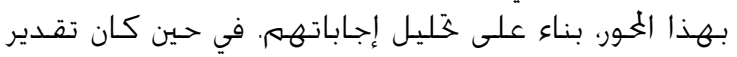

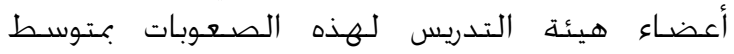

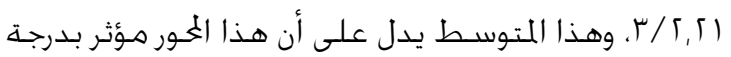

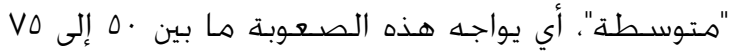

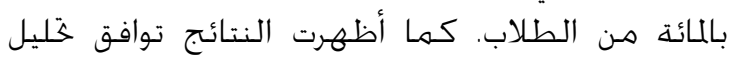

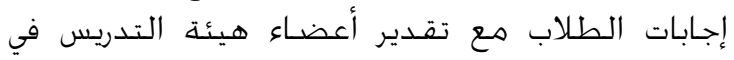

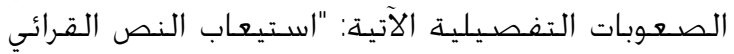

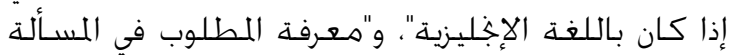

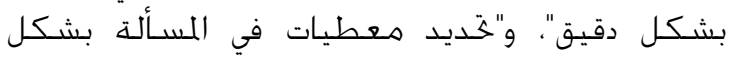

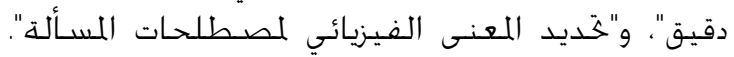

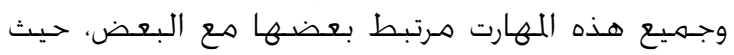

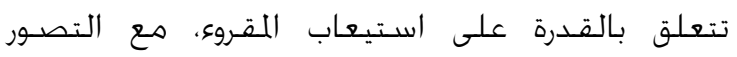

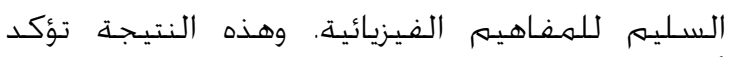
أهمية العناية بجانبين مهمين، وهما: العناية بصياغة العيانة

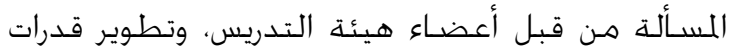

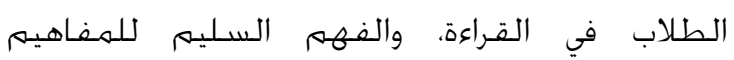
الفيزيائية. 


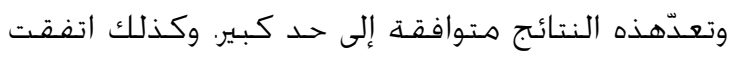

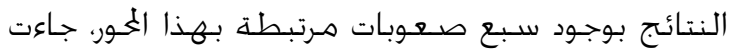
خمس منها متعلقة باختيار واستخدام القوانين المناسبة، تمثلت بالتالي: "اختيار المعادلة (القانون) المناسبة المتانين

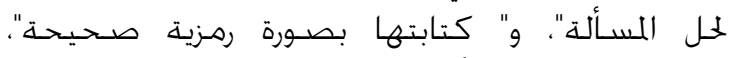

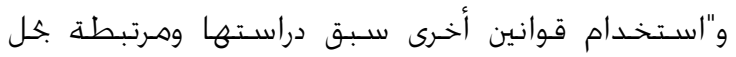
المسـألة"، و"اشتقاق معادلات فرعية من القانون الرئيس" الريس

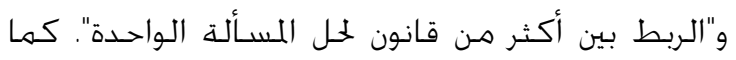

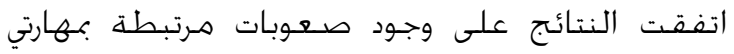

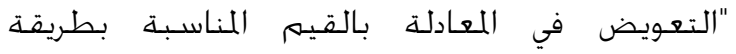

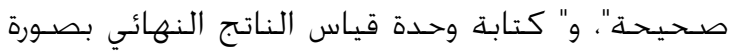

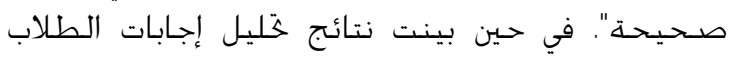

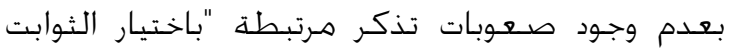

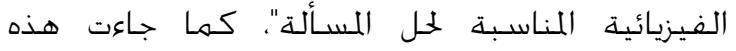

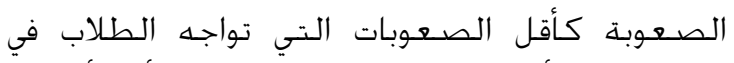

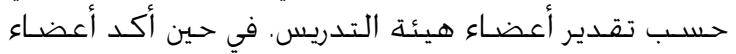

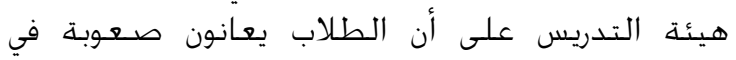

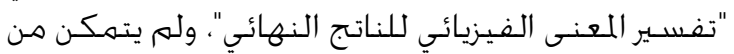

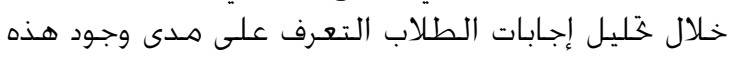
الصعـوبة.

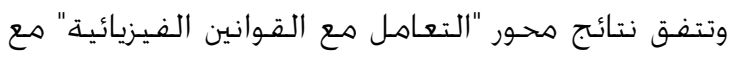

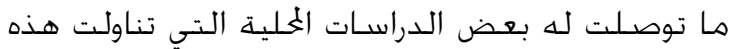

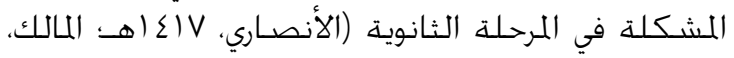

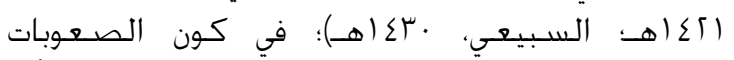

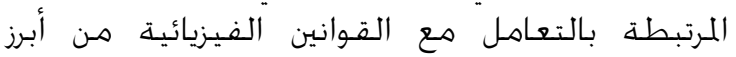

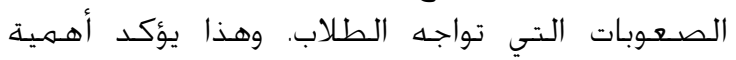

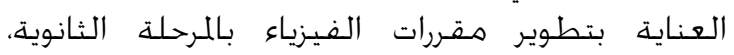

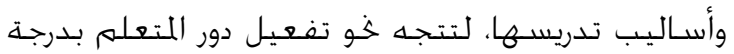

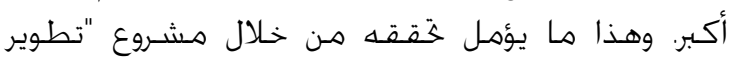

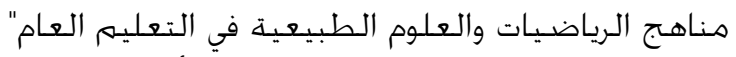

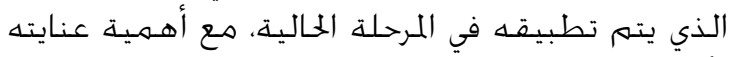

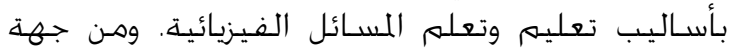

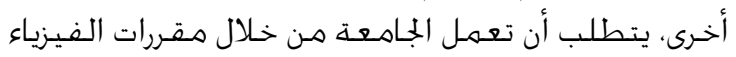

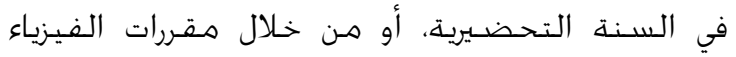

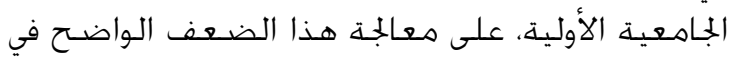

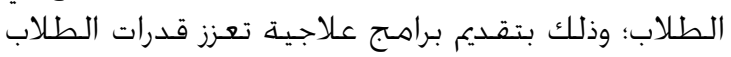

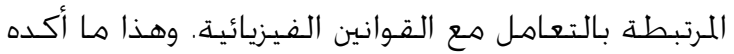

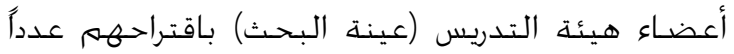

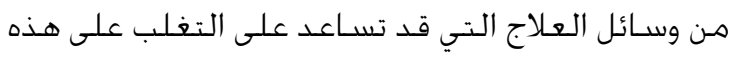

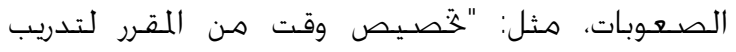

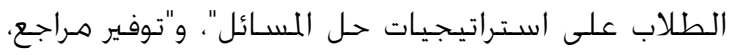

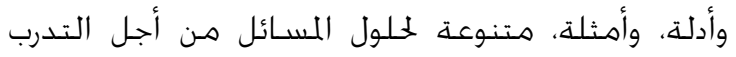

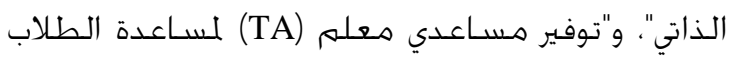

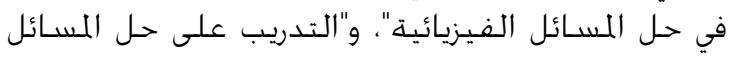

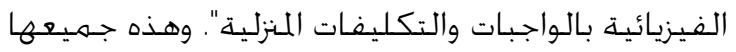

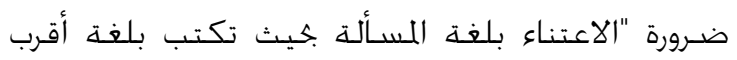

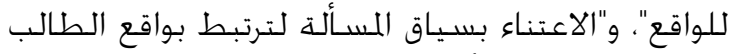

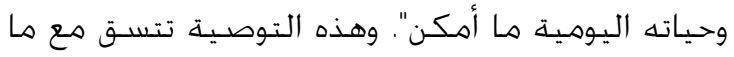
توصلت إليه عدد من الدراسات التي تناولت صياغ التهة

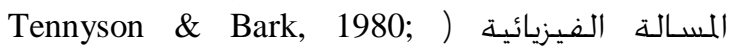
Bagayoko, Kelley \& Hasan, 2000; Park \& Lee, دراس 2005

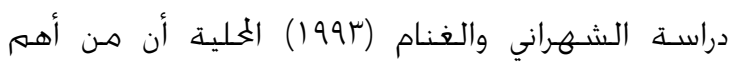

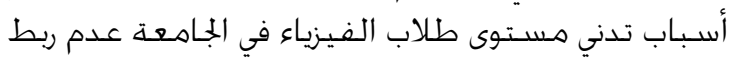

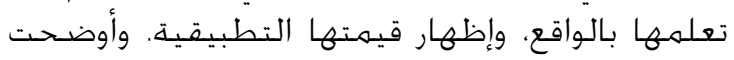

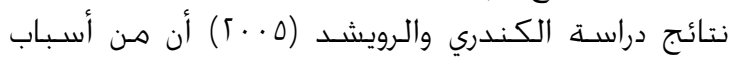

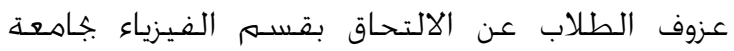

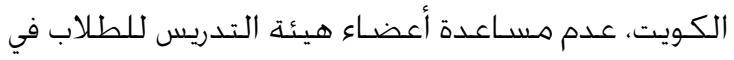

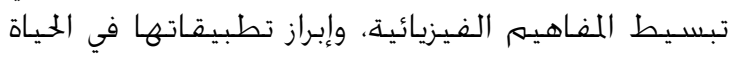
اليـوهيـة.

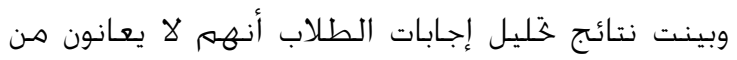

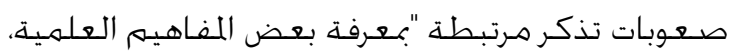

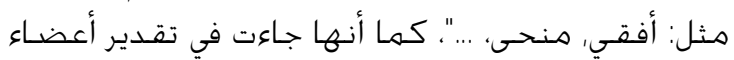

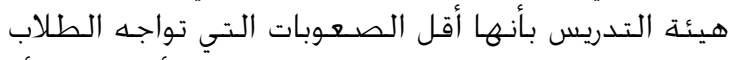

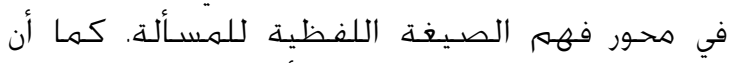

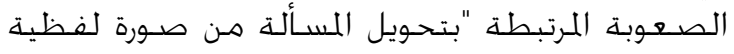

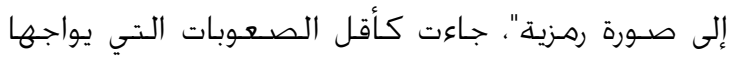

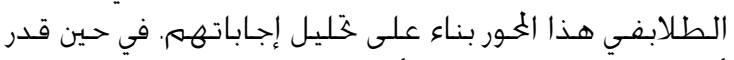

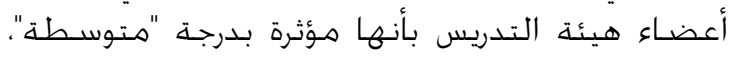

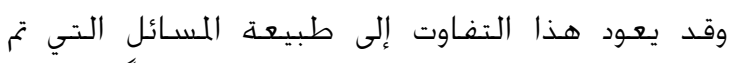

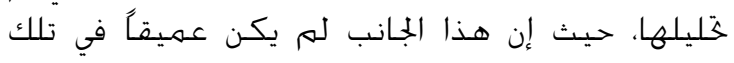

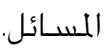

وبينت نتائج الدراسـات التي تناولت صعـوبات حل المسائل

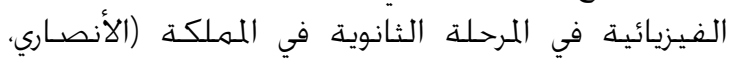

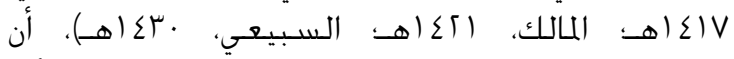

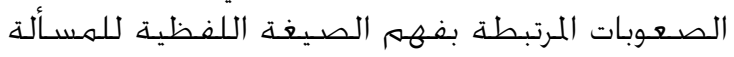

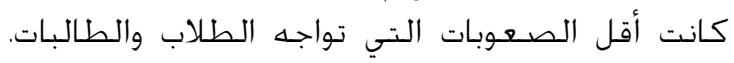

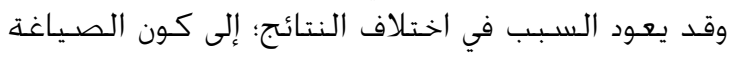

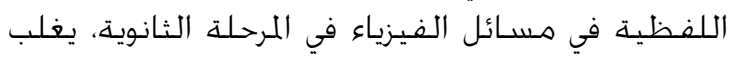

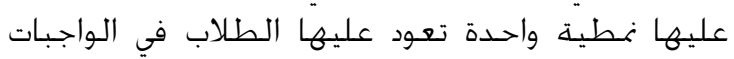

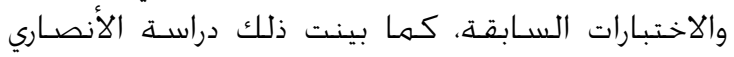

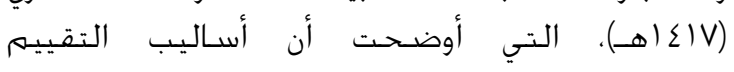

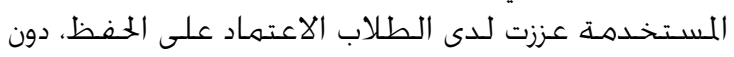

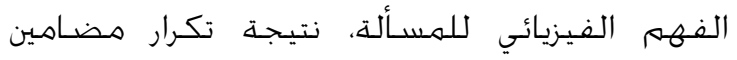

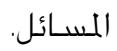

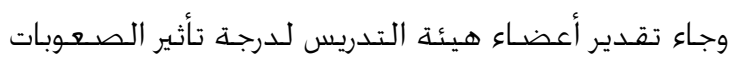

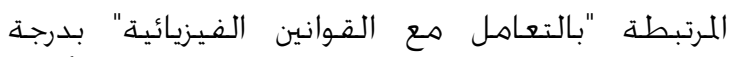

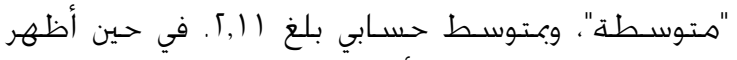

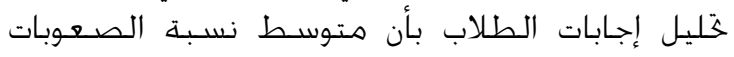

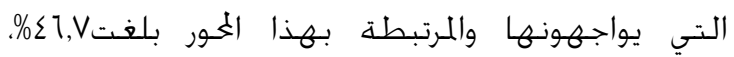


باعتبارها أحد أهم الجمالات التي يتبغي على طالب

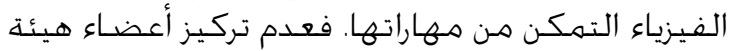

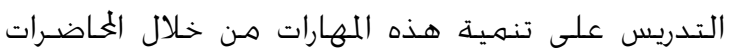

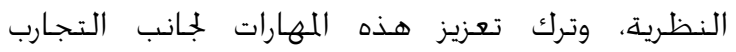

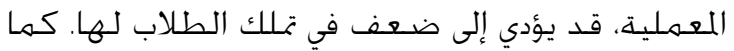

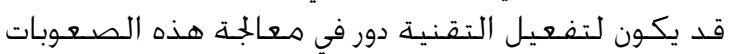

.(Alshaya, 2003; Ross, \& Casey, 1994)

وجاءت الصعوبات المرتبطة "بالمهارات الرياضية" كأقل

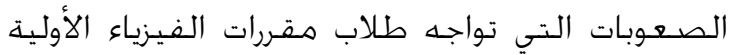

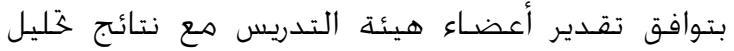

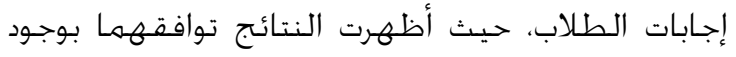
صعوبتين فقط، وهما: "القدرة على منطقية التهبة التقدير

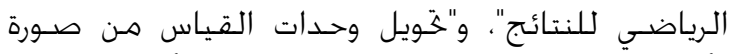

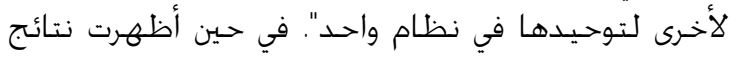

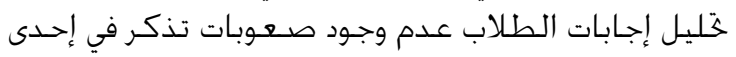

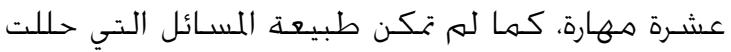

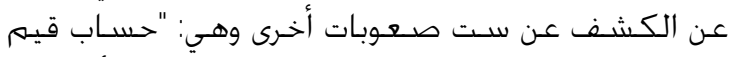

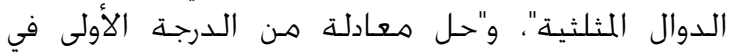

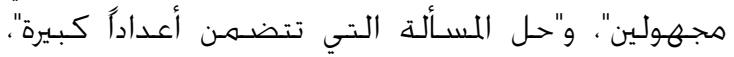

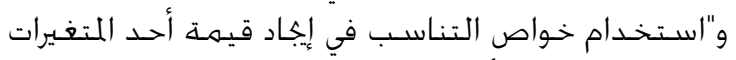

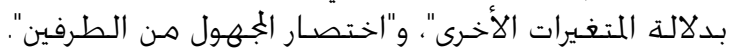

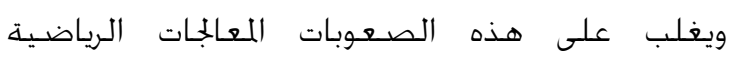

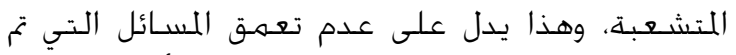

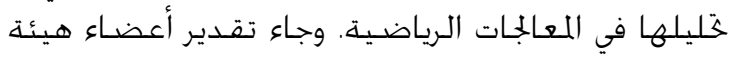

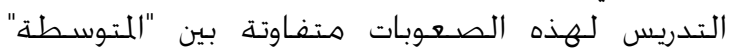
و" القليلة".

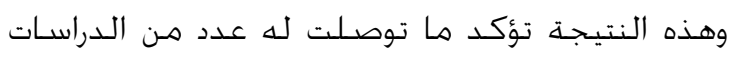
(Redish, 2005; Cui, Rebello \& Bennett, السابقة 2005 بعدم ترابط ها يدرسـ الطلاب في مقررات

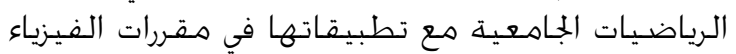

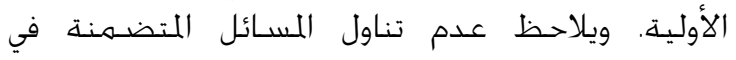

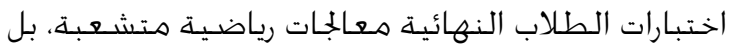

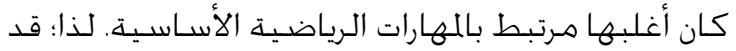

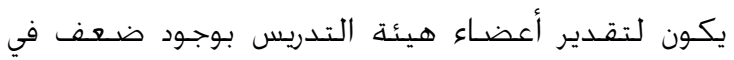

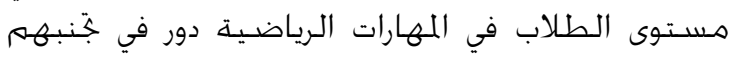

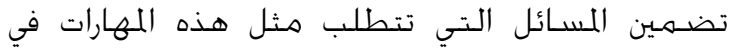
الاختبارات النهائية للطبلاب.

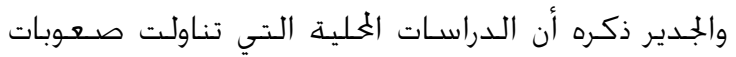

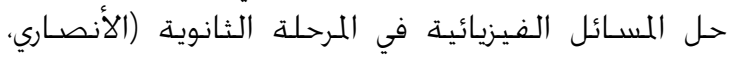

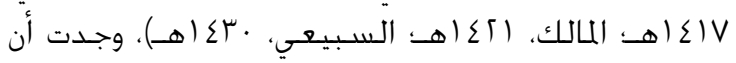

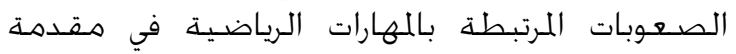

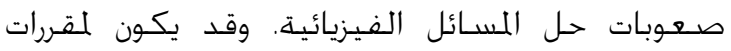

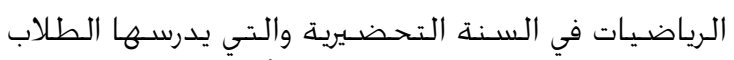

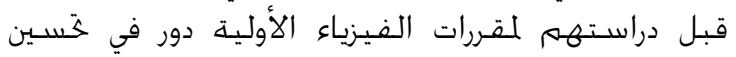
قدرات الطلاب في المهارات الرياضية، والتي اعتبرها في الإلية
وسـائل أكـدت على فاعليتها عدد من الدراسـات السـابقة

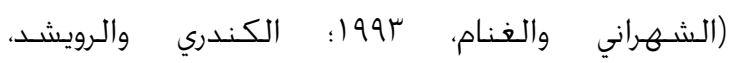
Bagayoko, Kelley \& Hasan, 2000): $\lceil$. o

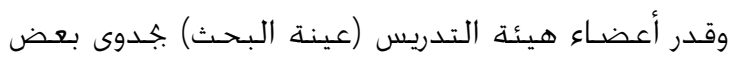

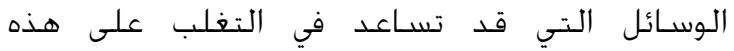

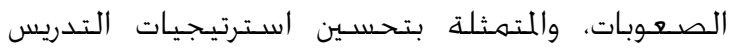

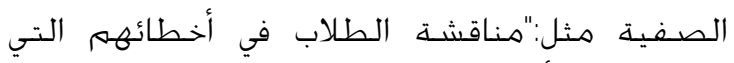

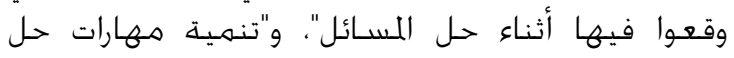
المسائل، مثل: توقع الإجابة قبل الحل، والتأكد بعل بعده".

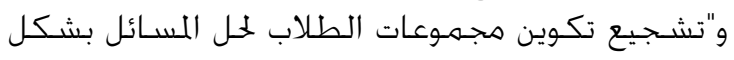

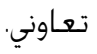
وأظهرت النتائج توافق تقدير أعضاء هيئة التدريس

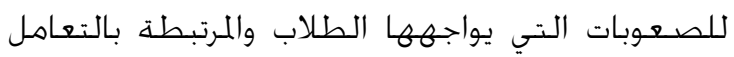

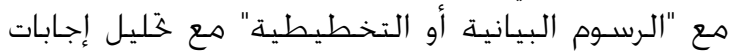

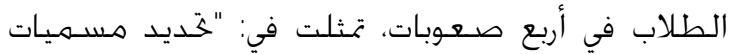

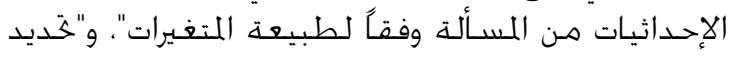

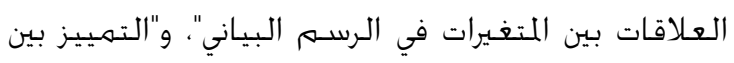

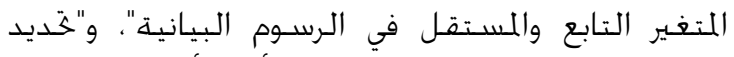

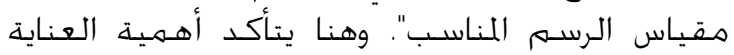

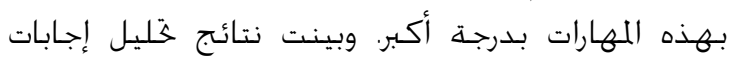

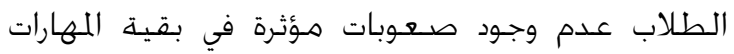

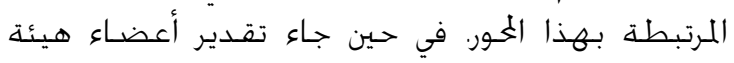

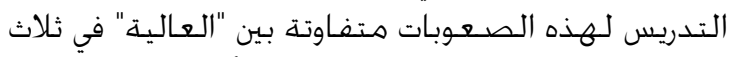

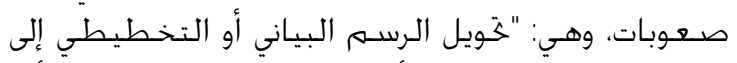

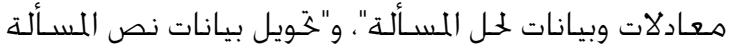

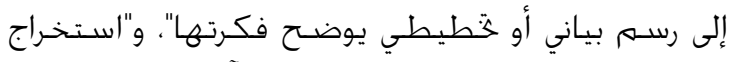

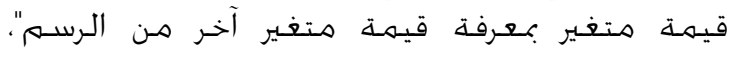

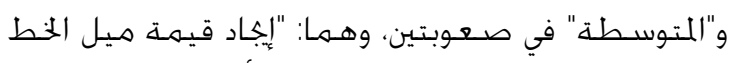

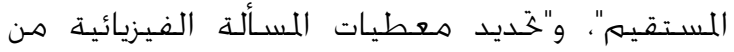

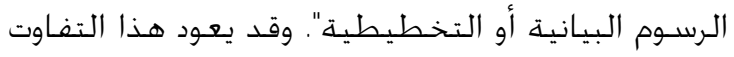

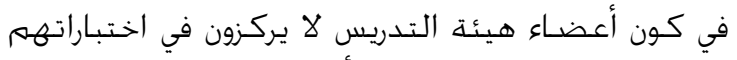

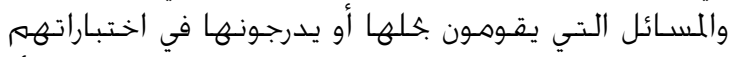

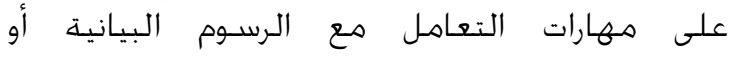

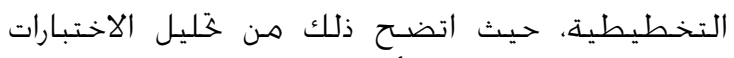

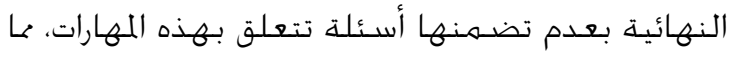

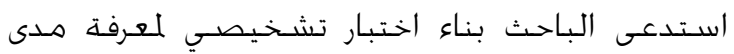

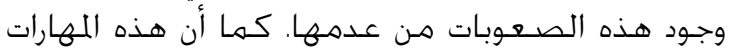

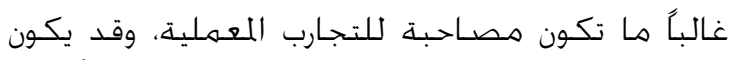

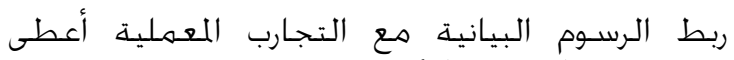

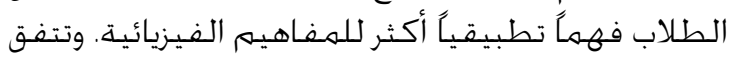

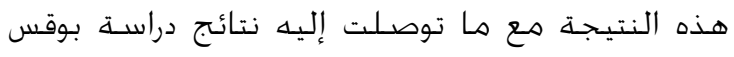

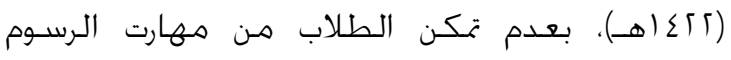
البيانية والتخطيطية.

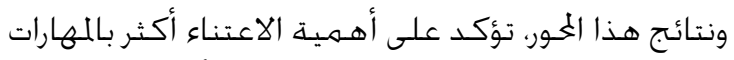

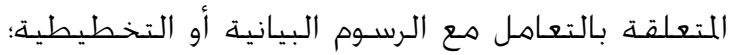


المتعلم في غتسين مهارات الطلاب في حل المسائل الفيزيائية.

إعادة إجراء هذه الدراسـة بعد ثلاثة أعوام، حيث

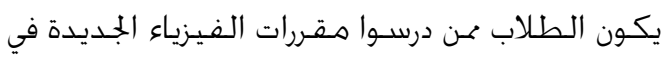

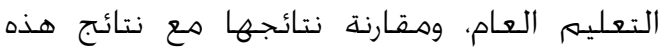
الدراسـة. شكر وتقديز: - ان

يتقدم الباحث بالشكر والتقدير لمركز التميز البحثي في لئن

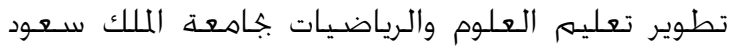

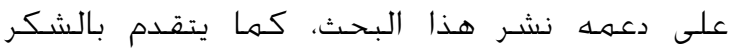

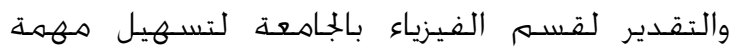

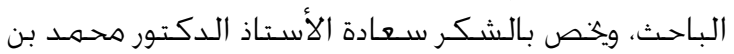

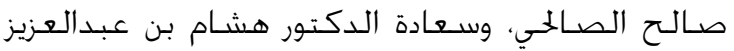

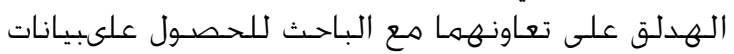

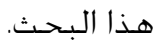

\section{المراجع}

\section{References}

ابن منظور، محهمد بن مكرم بن على (عاع (اعاهـ). لسـان العرب (طץّ). بيروت: دار صـادر.

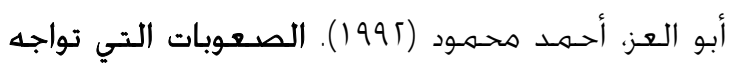

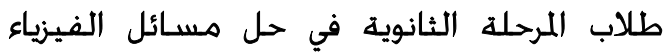

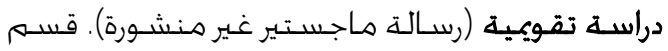

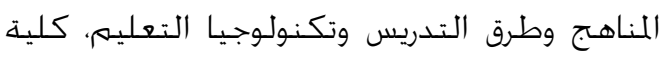
التربية، جامعة المنصورة: مصر.

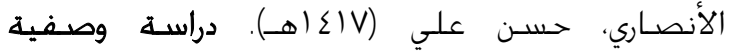

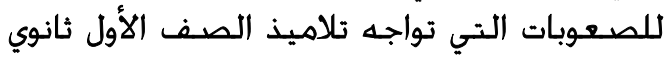
في حل المسائل اللفظية بمقرر الفيزياء وطرق العلاج

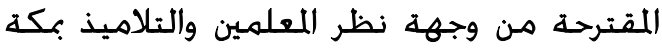

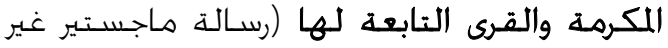

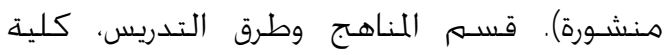
التربية، جامعة أم القـرى: مكة المكرمة.

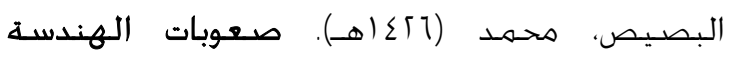

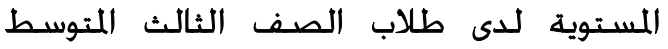

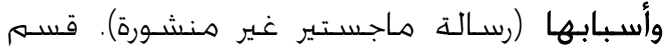

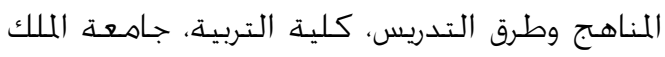

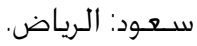

بوقس، جناة (آعاهـ). مستوى معرفة الطالبات المعلمات بكلية التربية للبنات بجدة (فيزياء -كيمياء)

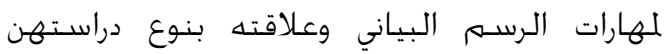

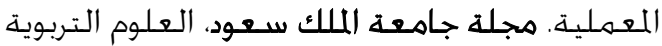

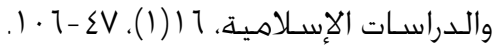

أعضاء هيئة التدريس (عينة البحث) الأكثر تأثيرً في

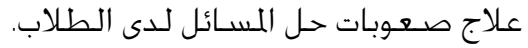

النوصيات: - الن

في ضـوء إجراءات هذه الدراسـة، وما توصلت إليه مـن نتائج، فإنه الباحث يوصـي بالآتي:

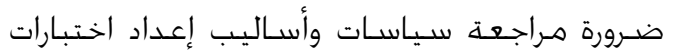

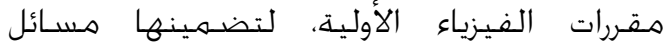

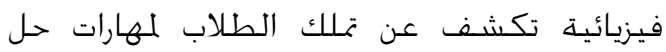
المسائل الفيزيائية، وعدم الاعتماد على تلى الأسئلة الموضـوعية بشكل رئيس.

أهمية عناية أعضاء هيئة التدريس في صياغة

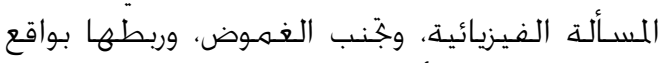
الحياة البومية (ما أمكن).

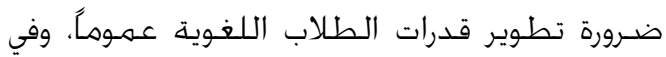

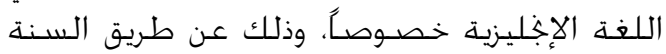

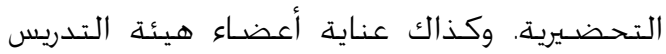
بهذا الجانب في تدريسهم المقررات.

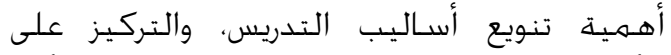

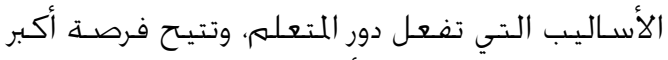

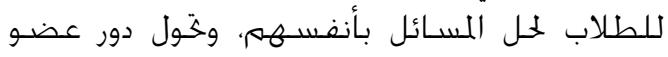
هيئة التدريس من التركيز على الحماضـرة إلى تقديم الدعم والمشـورة للطالب. تكثيف حل المعهائل المبائل من قبل قبل الطلاب، عن طريق

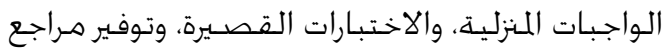

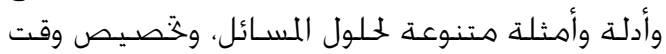

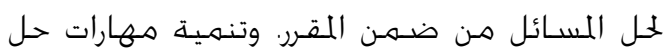

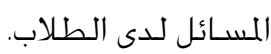

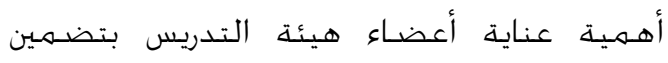

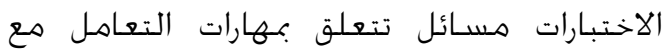

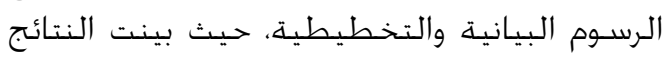
عدم احتواء المسائل في الاختبارات النهائية على الى لرائ هذا الجانب. تفعيل اسـتخدام التقنية في تعليم الفيزياء عموماً،

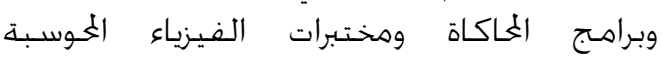

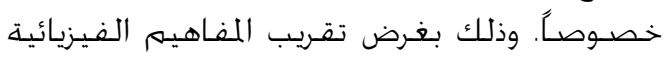

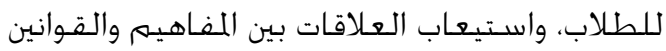
الفيزيائية.

كما يُوصى بمواصلة البحث في الموضوعات التالية: إجراء دراسـة مماثلة على طالبات مقررات الفيزياء

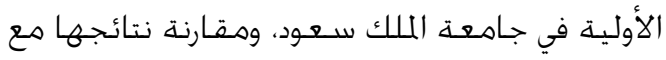
نتائج هذه الدراسـة.

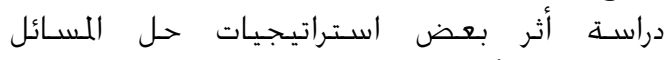
الفيزيائية، وأسـاليب تدريس الفيزياء المفعلة لدور الدانيات 
مصـطفى، إبراهيم: والزيات، أحسمد؛ وعبدالقـادر، حامد؛

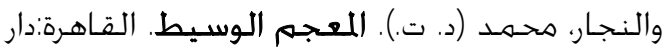

الدعوة.

وزارة التربية والتعليهم (د. ت.). مشـروع تطوير الرياضيات

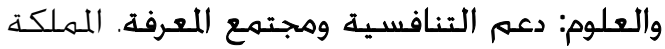

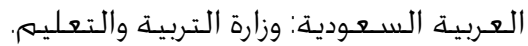

Alshaya, F. (2003). The effect of microcomputer based laboratory (M BL) on students' learning of capacitor experiment in introductory college physics courses in Saudi Arabia. Unpublished doctoral dissertation, University of Pittsburgh: USA.

Bagayoko, D., Kelley, E., \& Hasan, S.(2000). Problem-solving paradigm. College Teaching, 48(1), 24-27.

Bolte, J.(1966). Background factors and success in college physics. Journal of Research in Science Teaching, 4(2), 74-78.

Brekke, S. (1996). A spects of the cognitive model of physics problem solving. Report, Retrieved: 12 May, 2011, from: http:/ / www. eric. ed. gov/ PDFS/ ED401125. pdf.

Cui, L., Rebello, S., \& Bennett, A. (2005). College students' transfer from calculus to physics. Paper presented at Physics Education Research Conference, American Institute of Physics, 1011 A ugust, Salt Lake City, Utah, USA.

Fuller, R. (1982). Solving physics problem: How do we do it? Physics Today, 35(9), 43-47.

Henderson, C., Heller, K., Heller, P., Kuo, V., Yerushalmi, E. (2002). Students learning problem solving in introductory physics: Forming an initial hypothesis of instructors' beliefs. Paper presented at the Physics Educational Research Conference, Boise, ID, August 7-8.

Kuo, V., Heller, K., Heller, P., Henderson, C., Yerushalmi, E. (2002). Teaching students problem solving in introductory physics: Forming an initial hypothesis of instructors' beliefs. Paper presented at the Physics Educational Research Conference, Boise, ID, August 7-8.

Park, J., \& Lee, L. (2004). A nalysing cognitive or non-cognitive factors involved in the process of physics problem-solving in an everyday context. International Journal of Science Education, 26(13), 1577-1595.

Redish, E. F. (2005). Problem solving and the use of math in physics courses. Paper presented at World View on Physics Education: Focusing on Change, India: Delhi, August 21-26.

Ross, S. M., \& Casey, J.(1994). U sing interactive software to devel op students' problem-solving skills: Evaluation of the "Intelligent Physics Tutor". Paper presented at $\mathrm{N}$ ational Convention of the Association for Educational Communications and Technology, Nashville, TN, February 1620.

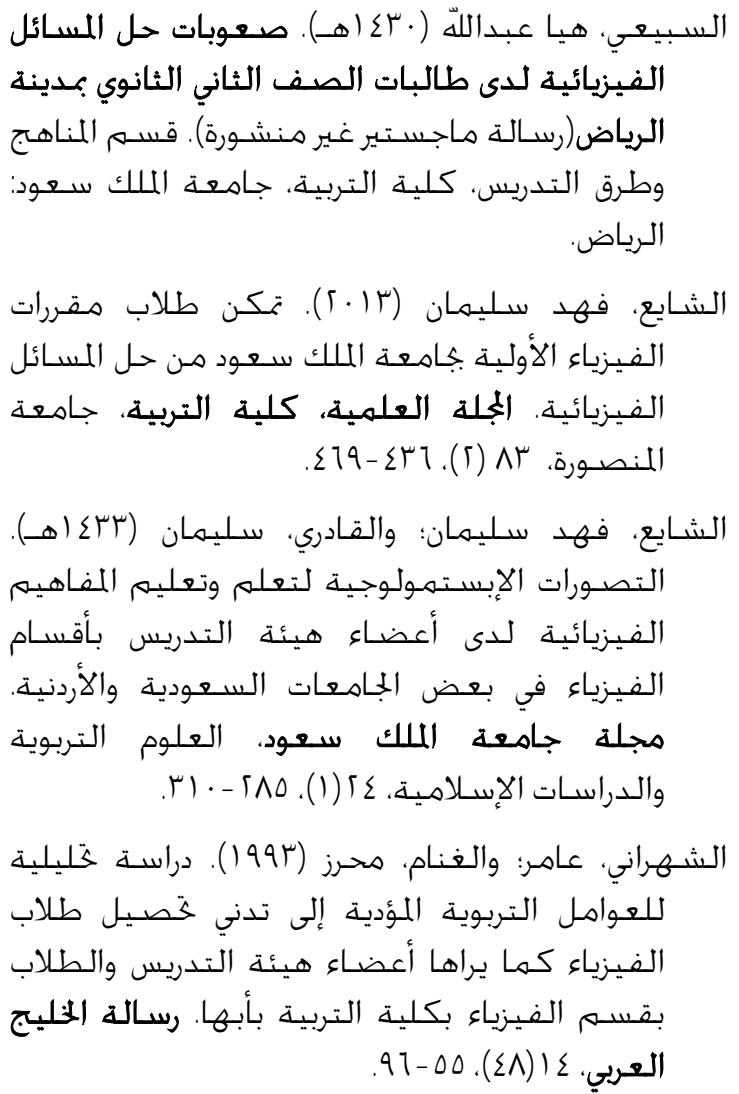

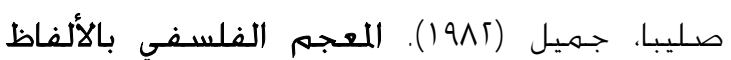

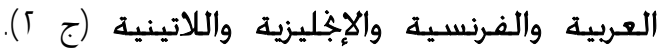
بيروت: دار الكتاب اللبناني.

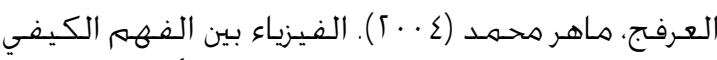

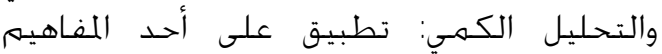

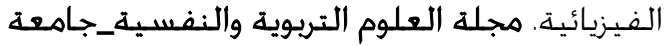

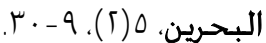

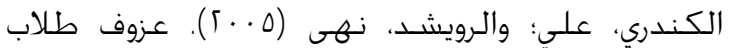

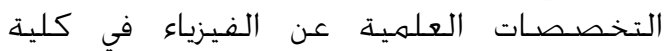

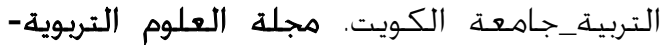

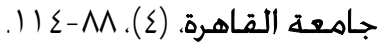

المالك، فاطمة (آعا(هـ). فاعلية استراتيجية تدريس

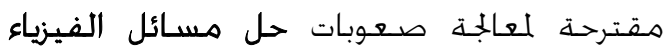

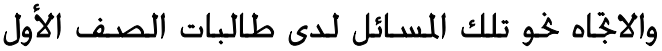

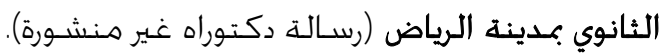

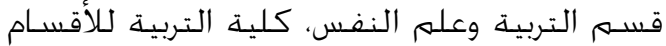
الأدبية: الرياض. المتربية

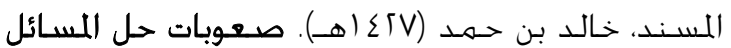

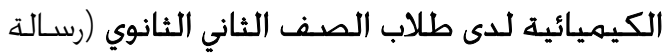

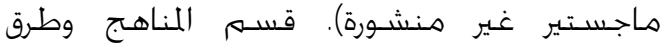

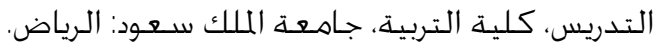


Sadler, P., \& Tai, R. (2001). Success in introductory college physics: The role of high school preparation. Science Education, 85(2), 111-136.

Sambs, H.(1991). Problem solving in physics and mathematics: What do they have in common? (Creating a base for research and teaching). Paper presented at the Annual Meeting of the National Association for Research in Science Teaching, Lake Geneva, WI, A pril 7-10.

Tennyson, R., \& Bark, B. (1980). The teaching of concept: A review of instructional design research literature. Review of Educational Research, 50(1), 55- 70.

Thorsland, M., \& Novak, J. (1972). The identification and significance of intuitive and analytic problem solving approaches among college physics students. Paper presented at the annual meeting of the National Association for Research in Science Teaching, Chicago, USA, A pril 4.

Yager, R., \& Krajcik, J. (1989). Success of students in a college physics courses with and without experiencing a high school course Journal of Research in Science Teaching, 26(7), 599-608. 